\title{
¿Estimating Rain Microphysical Characteristics Using S-Band Dual-Polarization Radar in South Korea
}

\author{
HAE-Lim Kim, Sung-Hwa Jung, AND Kun-IL JANG \\ Radar Analysis Division, Weather Radar Center, Korea Meteorological Administration, Seoul, South Korea
}

(Manuscript received 19 April 2019, in final form 12 February 2020)

\begin{abstract}
Raindrop size distribution (DSD) observed using a disdrometer can be represented by a constrainedgamma (C-G) DSD model based on the empirical relationship between shape $(\mu)$ and slope $(\Lambda)$. The $\mathrm{C}-\mathrm{G}$ DSD model can be used to retrieve DSDs and rain microphysical parameters from dual-polarization radar measurements of reflectivity $\left(Z_{H}\right)$ and differential reflectivity $\left(Z_{\mathrm{DR}}\right)$. This study presents a new $\mu-\Lambda$ relationship to characterize rain microphysics in South Korea using a two-dimensional video disdrometer (2DVD) and Yong-in S-band dual-polarization radar. To minimize sampling errors from the 2DVD and radar measurements, measured size distributions are truncated by particle size and velocity-based filtering and compared with rain gauge measurement. The calibration biases of radar $Z_{H}$ and $Z_{\mathrm{DR}}$ were calculated using the self-consistency constraint and vertical pointing measurements. The derived $\mu-\Lambda$ relationship was verified using the mass-weighted mean diameter $\left(D_{m}\right)$ and standard deviation of the size distribution $\left(\sigma_{m}\right)$, calculated from the 2DVD, for comparison with existing $\mu-\Lambda$ relationships for Florida and Oklahoma. The $D_{m}-\sigma_{m}$ relationship derived from the 2DVD corresponded well with the $\mu-\Lambda$ relationship. The $\mu-\Lambda$ relationship derived for the Korean Peninsula was similar to Florida, and both generally had larger $\mu$ values than Oklahoma for the same $\Lambda$. The derived $\mu-\Lambda$ relationship was applied to retrieve DSD parameters from polarimetric radar data, and the retrieved DSDs and derived physical parameters were evaluated and compared with the 2DVD measurements. The polarization radar-based C-G DSD model characterized rain microphysics more accurately than the exponential DSD model. The C-G DSD model based on the newly derived $\mu-\Lambda$ relationship performed the best at retrieving rain microphysical parameters.
\end{abstract}

\section{Introduction}

Raindrop size distributions (DSDs) are highly useful for understanding rain microphysics, estimating rainfall, and improving microphysical parameterization in numerical weather prediction (NWP) models (Steiner et al. 2004). Rain DSDs can be characterized through disdrometer and dual-polarization radar measurements. DSDs observed with a disdrometer can then be represented by various DSD models, such as exponential or gamma models. However, exponential DSD models containing two parameters [e.g., intercept $\left(N_{o}\right)$ and slope $(\Lambda)$, cannot capture instantaneous rain DSDs. Therefore, a more general DSD model is required.

๑ Denotes content that is immediately available upon publication as open access.

Corresponding author: Hae-Lim Kim, hlk0919@korea.kr
Ulbrich (1983) presented a gamma DSD model with $N_{o}$, $\Lambda$, and shape $(\mu)$ parameters that naturally described DSDs. This is because $\mu$ and $\Lambda$ describe different spectra and shapes of DSDs (e.g., Brandes et al. 2003, 2004b; Zhang et al. 2006). More recently, the constrained-gamma (C-G) DSD model has been used to retrieve rain DSDs from dual-polarization radar measurements using a constraining relationship between the $\mu$ and $\Lambda$ values of the distribution (Zhang et al. 2001). Zhang et al. (2001) and Brandes et al. (2004a) found a high correlation between $\mu$ and $\Lambda$ from disdrometer observations. The C-G model based on this $\mu-\Lambda$ relationship has been used to study storm microphysics and improve the accuracy of rainfall estimation by retrieving rain DSDs (e.g., Brandes et al. 2004a; Vivekanandan et al. 2004).

The inclusion of specific differential phase $\left(K_{\mathrm{DP}}\right)$ measurements increases the accuracy of DSD retrieval and rain microphysical parameter estimation (Huang 
et al. 2019). In addition, various studies have quantitatively evaluated DSD retrievals using disdrometer measurements (e.g., Haddad et al. 1997; Bringi et al. 2002, 2003; Gorgucci et al. 2002; Brandes et al. 2004a,b; Vivekanandan et al. 2004; Zhang et al. 2001, 2006). Although the $\mu-\Lambda$ relationship facilitates DSD parameter retrieval, spatial differences are observed in this relationship for different climate regions and between precipitation types (e.g., Cao et al. 2008; Cao and Zhang 2009). For example, the $\mu-\Lambda$ relationship for the southern Great Plains in Oklahoma differs from that for subtropical Florida (e.g., Zhang et al. 2001; Brandes et al. 2004a,b). The Korean Peninsula is surrounded by the sea on three sides and the climate is characterized by four distinct seasons. Nevertheless, these $\mu-\Lambda$ relationships have not been studied extensively for the Korean Peninsula. To address this, we derived a new $\mu-\Lambda$ relationship to reflect the rainfall characteristics of the Korean Peninsula using two-dimensional video disdrometer (2DVD) measurements. We then applied the newly derived $\mu-\Lambda$ relationship to the C-G DSD model to improve the accuracy of the DSD parameter retrieval from dualpolarization radar. The performance of DSD parameter retrievals was evaluated using the exponential DSD model and the C-G DSD model. The retrieved rain microphysical parameters were compared with the 2DVD observations. Quasi-vertical profile (QVP) data were used to analyze the microphysical and vertical structure of the two precipitation systems (Kumjian et al. 2013).

The remainder of this paper is organized as follows. Section 2 describes the 2DVD and radar data. The C-G DSD model, derivation of the $\mu-\Lambda$ relationship from the 2DVD data, and rain DSD parameter retrievals from polarization radar measurements are described in section 3 . In section 4 , the new $\mu-\Lambda$ relationship is compared with existing $\mu-\Lambda$ relationships including those of Zhang et al. (2001) and Cao et al. (2008). The retrieved rain microphysical parameters based on the DSD model from the $Z_{H}$ and $Z_{\mathrm{DR}}$ measurements of polarization radar are then evaluated using QVP and 2DVD data. Our conclusions are presented in section 5 .

\section{Data}

2DVD and rain gauge data from the ground observation station in Jincheon, South Korea $\left(37.0^{\circ} \mathrm{N}\right.$, $127.4^{\circ} \mathrm{E}, 448 \mathrm{~m}$ ), were used between April-October in 2014 and 2016. At this station, tipping-bucket type rain gauges with a resolution of $0.1 \mathrm{~mm}$ (RN01) were positioned $8 \mathrm{~m}$ to the south and west of the 2DVD.

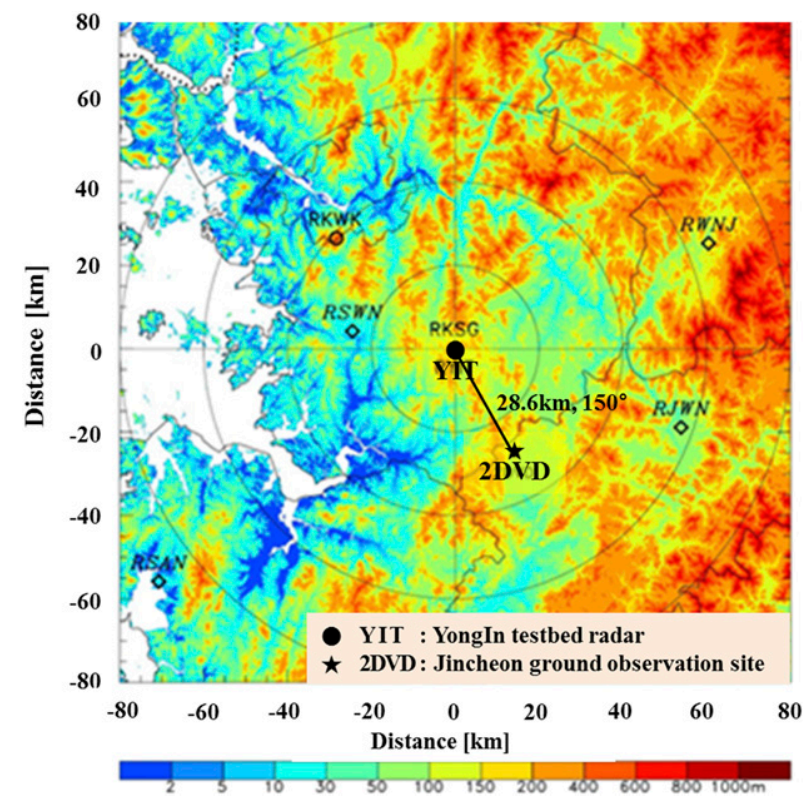

FIG. 1. Locations of the Yong-In Testbed (YIT) radar and Jincheon ground observation site.

Data were collected for a total of 110 rain events, which included various types of precipitation. The radar data were collected from the Yong-In Testbed (YIT) S-band dual-polarization radar $\left(37.2^{\circ} \mathrm{N}, 127.3^{\circ} \mathrm{E}\right.$, $138.4 \mathrm{~m}$ ) as operated by the Korea Meteorological Administration (KMA).

The Jincheon ground observation station (hereafter Jincheon station) is equipped with a 2DVD, PARSIVEL, rain gauge, and an automatic weather system to verify the dual-polarization radar output. It has been in operation since April 2014. Jincheon station is located approximately $28.6 \mathrm{~km}\left(150^{\circ}\right)$ from the YIT (Fig. 1).

\section{a. $2 D V D$}

A 2DVD was installed $0.9 \mathrm{~m}$ above the ground to prevent the effects of strong surface turbulence (Fig. 2a). The 2DVD consisted of a halogen lamp, orthogonal light sheets, and photo detectors (Fig. 2b). The particle images were detected on the photo detector, and the drop size, fall velocity, and shape of individual raindrops were recorded from two sides and at different heights as raindrops fall through the measurement area $\left(10 \times 10 \mathrm{~cm}^{2}\right)$.

The 2DVD is very sensitive to the surrounding environment, including wind turbulence, insects, and pollen. Some particle outliers were recorded due to some mismatching between camera A and B, splashing, and the breakup of raindrops (Figs. 3a,b) (Raupach and Berne 2015). In addition, the 2DVD observations were affected by low instrument sensitivity, wind effects, and 

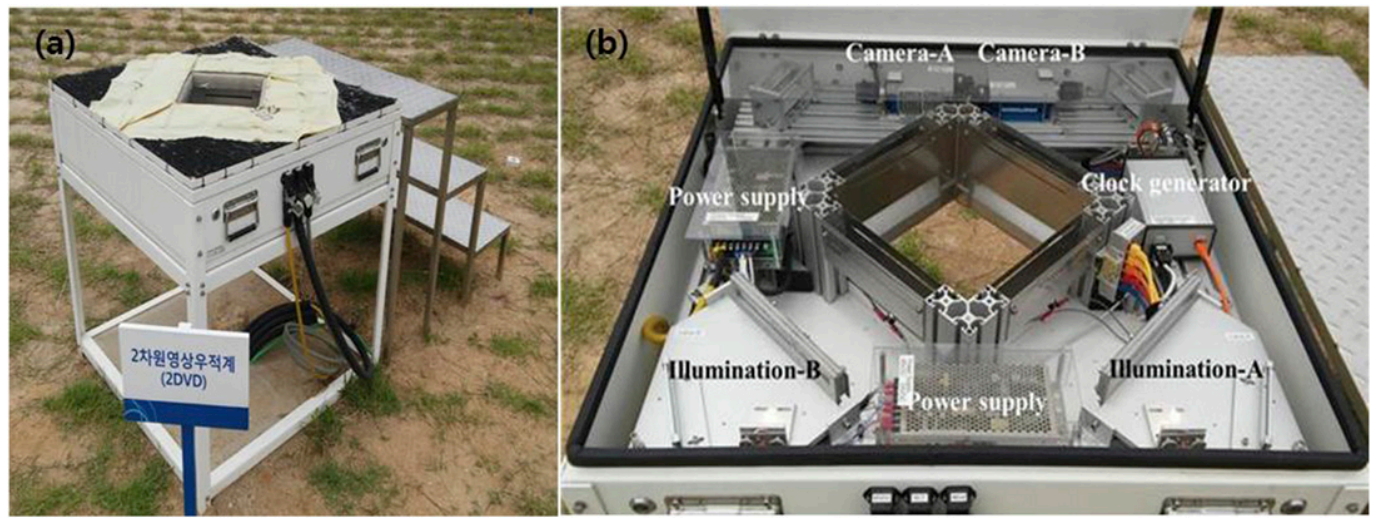

FIG. 2. Photographs of the 2DVD (a) outdoor unit and (b) interior view of the outdoor unit at the surface validation site.

limited sample volume in measuring small and large drops. Thus, the quality control of 2DVD measurements and DSD truncation are important to express the natural gamma distribution (e.g., Vivekanandan et al. 2004;
Moisseev and Chandrasekar 2007). To improve the accuracy of the 2DVD data and remove outliers, the velocity-based filtering method of Kruger and Krajewski (2002) was applied, as shown in Eq. (1):
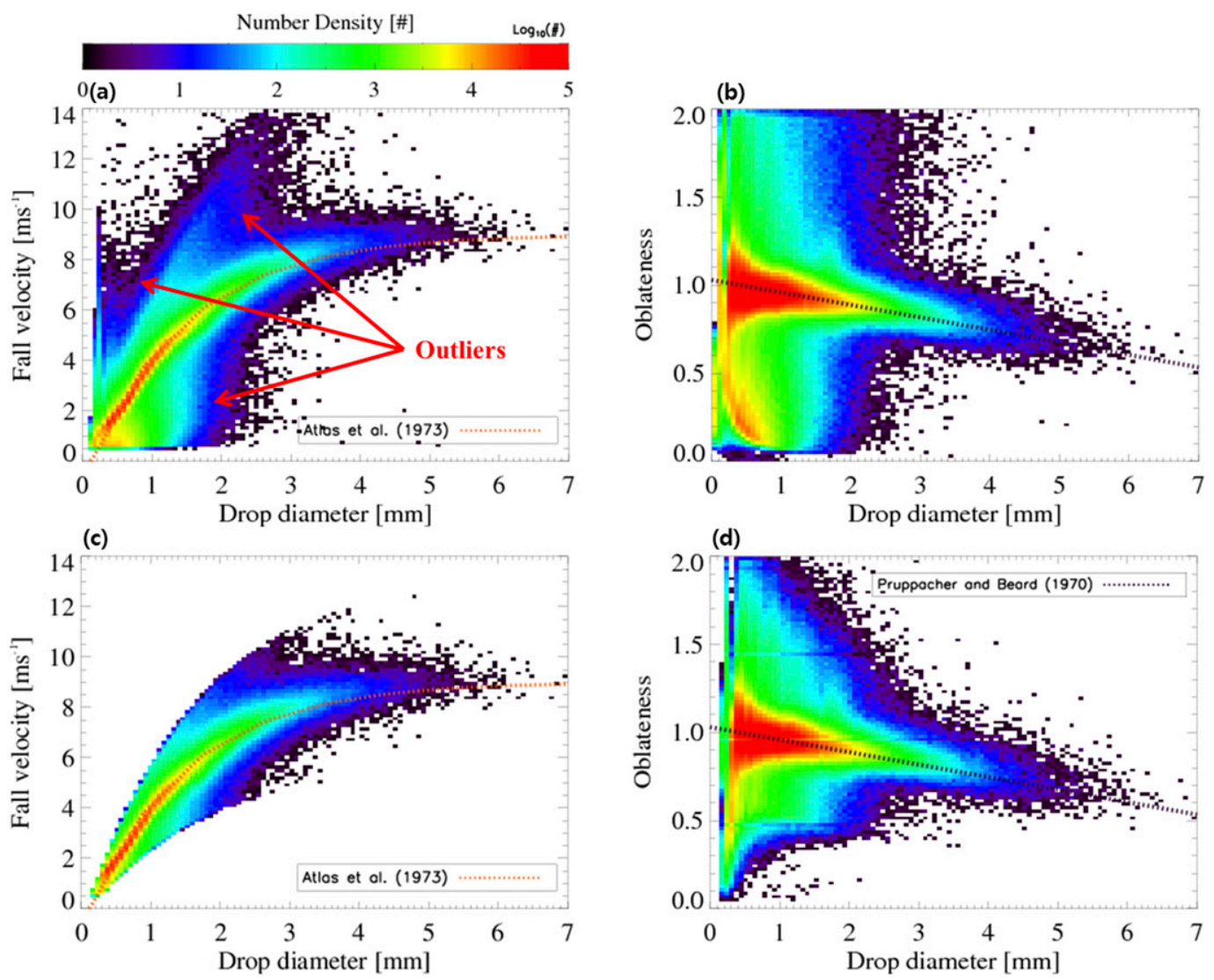

FIG. 3. Distribution of fall velocity and oblateness according to drop diameter: (a) velocity-based filter for the drop measurements. The color scale represents the drop number density (log scale). The orange dotted line represents the results using the velocity formula of Atlas et al. (1973); (b) drop axis ratios for all measured drops; (c) drop falling velocity after removing mismatched drops; and (d) drop axis ratios after removing mismatched drops. The black dotted line represents the mean axis-ratio results from the formula given in Pruppacher and Beard (1970). 


$$
\begin{aligned}
& \left|V_{\text {measured }}(D)-V_{A}(D)\right|<0.4 V_{A}(D) \\
& V_{A}(D)=9.65-10.3 \exp (-0.6 D),
\end{aligned}
$$

where $D(\mathrm{~mm})$ is the drop diameter, $V_{\text {measured }}$ is the fall velocity $\left(\mathrm{m} \mathrm{s}^{-1}\right)$ measured by the $2 \mathrm{DVD}$, and $V_{A}$ represents the Atlas velocity formula (Atlas et al. 1973). As a result, the majority of outliers in the small raindrop size ranges were removed (Figs. 3c,d).

To analyze the reliability of the 2DVD data, the rain rates calculated from the 2DVD data [Eq. (2)] were compared with three rain gauge measurements, and the average rainfall of three $0.1 \mathrm{~mm}$ rain gauges was compared with the 2DVD rainfall to mitigate for any finescale spatial variability in precipitation. Rain gauge measurements can only verify the middle moment of rain DSDs, but not all the information contained in the DSDs. Even small precipitation differences between 2DVD and the rain gauge can substantially affect radar reflectivity and number concentration. However, the precipitation was compared using a rain gauge installed at the same point as 2DVD to select the better-observed cases with less error:

$$
R=6 \pi \times 10^{-4} \sum_{0}^{D_{\max }} D^{3} V(D) N(D) \Delta D,
$$

where $D_{\max }$ is the maximum diameter of the observed drops $\left(D_{\max }=8 \mathrm{~mm}\right), V(D)$ is the Atlas fall velocity formula in $\mathrm{m} \mathrm{s}^{-1}$, and $N(D)$ is the drop size distribution in $\mathrm{mm}^{-1} \mathrm{~m}^{-3} ; N(D)$ has a total of 40 channels up to the $D_{\max }$ per drop interval $(\Delta D=0.2 \mathrm{~mm})$. In this study, 2DVD data of fewer than five channels were removed for continuity.

Figure 4 shows the accumulated rainfall amount and hourly rain rate obtained from the 2DVD and rain gauges. The gray shaded area denotes the amount of accumulated rainfall estimated from the 2DVD; the red solid, dotted, and dashed lines represent the amount of rainfall accumulated as measured from the three $0.1-\mathrm{mm}$ rain gauges, respectively. The black solid line denotes the mean accumulated rainfall as averaged across the three rain gauges. The two events shown in Figs. 4a and 4c occurred at 0200-1000 KST 27 October 2015, and 0100-1100 KST 25 October 2016. The amount of rainfall recorded by the 2DVD shows good agreement with the gauge data. Storms with an hourly average rainfall of $5 \mathrm{~mm} \mathrm{~h}^{-1}$ or less passed over Jincheon station (Fig. 4b) and total accumulated rainfall amounts of 18.2 and $15.3 \mathrm{~mm}$ were recorded by the rain gauge and 2DVD (Fig. 4a), respectively. On 25 October 2016, when the hourly rainfall rate was less than $8 \mathrm{~mm} \mathrm{~h}^{-1}$ (Fig. 4d), the rain gauge and 2DVD recorded 32.5 and $28.1 \mathrm{~mm}$ (Fig. 4c). Thus, for both events, the total rainfall amounts recorded by the 2DVD were less than those recorded by the rain gauge. The 2DVD mostly underestimated the total rainfall amount due to wind turbulence, splashing, and mismatched raindrops. In strongly windy conditions, small particles were blown out of the measurement area (Nešpor et al. 2000), and the splash guard was not effective during heavy rain (Tokay et al. 2001).

For these two events, the differences in the total rainfall amount recorded by the 2DVD and rain gauge were $15.8 \%$ and $13.6 \%$, respectively. In comparison, previous studies have shown that differences in rainfall measurements between rain gauges and disdrometers typically ranged between $10 \%$ and $20 \%$ (e.g., Mcfarquhar and List 1993; Sheppard and Joe 1994; Hagen and Yuter 2003; Tokay et al. 2003). Therefore, to derive $\mu-\Lambda$ relationship, only rainfall events were used for which the difference in rainfall amounts between the 2DVD and rain gauge was $<20 \%$.

\section{b. Radar}

In 2014, the Weather Radar Center (WRC) of the KMA installed the YIT S-band dual-polarization radar (model: DWSR-8501S/K/SDP, Enterprise Electronics Corporation). The YIT radar observation range is $240 \mathrm{~km}$ and covers most of the inland South Korean territory. The YIT radar measures polarization variables such as the $Z_{H}, Z_{\mathrm{DR}}$, differential phase $\left(\Phi_{\mathrm{DP}}\right), K_{\mathrm{DP}}$, and cross-correlation coefficient $\left(\rho_{\mathrm{hv}}\right)$ in real time. Vertical pointing observations that fix the elevation angle at $90^{\circ}$ and rotate the azimuth by $360^{\circ}$ are also performed every $30 \mathrm{~min}$. The specifications of the YIT radar are summarized in Table 1.

To retrieve rain microphysical parameters, the $Z_{H}$ and $Z_{\mathrm{DR}}$ of YIT radar were used and the radar data were averaged over five successive gates and two adjacent azimuth angles, centered on the 2DVD location for comparison with the 2DVD data. In addition, a second elevation angle of $0.61^{\circ}$ (or $0.48^{\circ}$ ) plan position indicator (PPI) was used to avoid ground effects. $Z_{H}$ and $Z_{\mathrm{DR}}$ are related to radar power, and their measurements suffer from system biases, such as antenna gain, receiver gain, hardware replacement, and miscalibration (Park and Lee 2010). Inaccurate calibration can lead to significant uncertainties in radar-based DSD retrieval. Thus, it is crucial to determine the calibration biases of $Z_{H}$ and $Z_{\mathrm{DR}}$ to achieve accurate DSD parameter retrieval. In this study, the daily calibration biases of $Z_{H}$ and $Z_{\mathrm{DR}}$ were calculated through $Z_{H}-K_{\mathrm{DP}}$ consistency and vertical pointing measurements, respectively. The details of a radar calibration methodology are described further in section $3 \mathrm{c}$. 
(a)

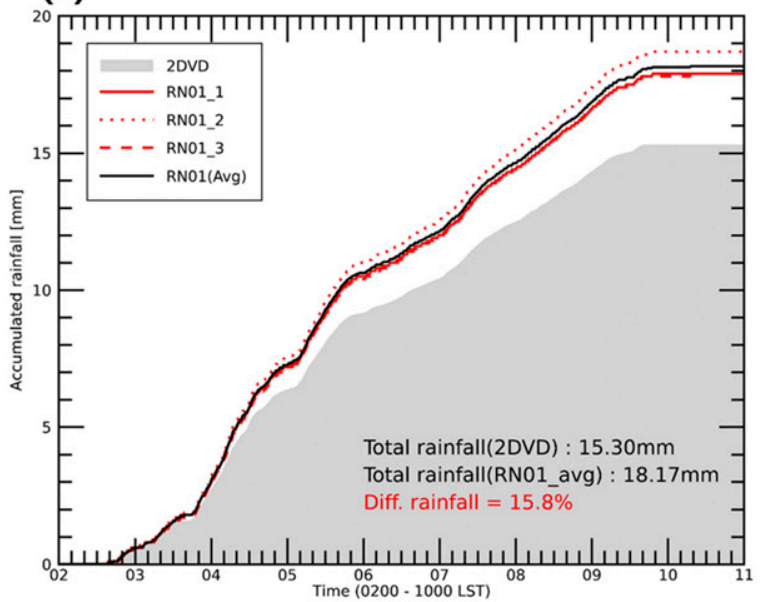

(c)

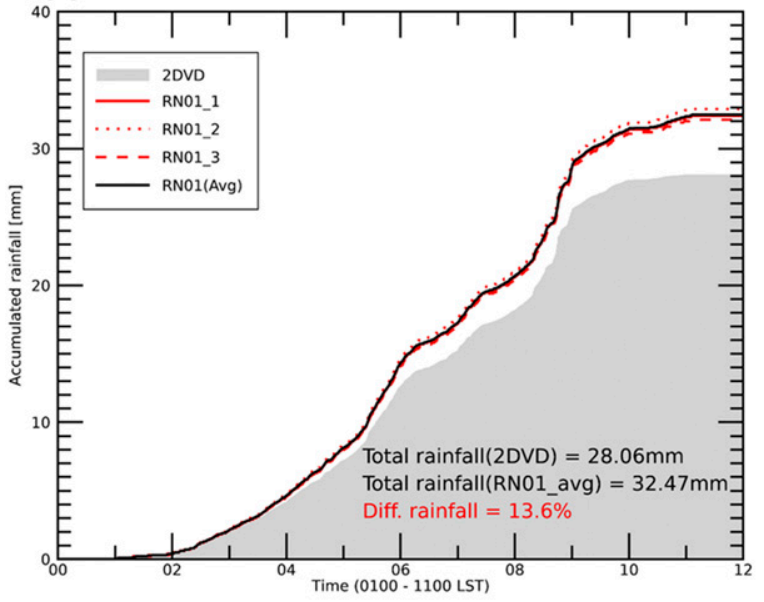

(b)

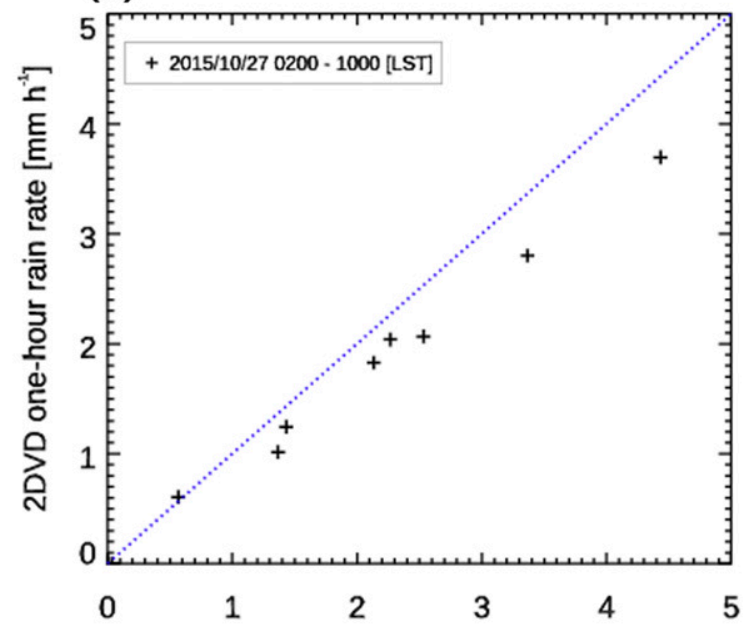

(d) Gauge one-hour rain rate $\left[\mathrm{mm} \mathrm{h}^{-1}\right]$

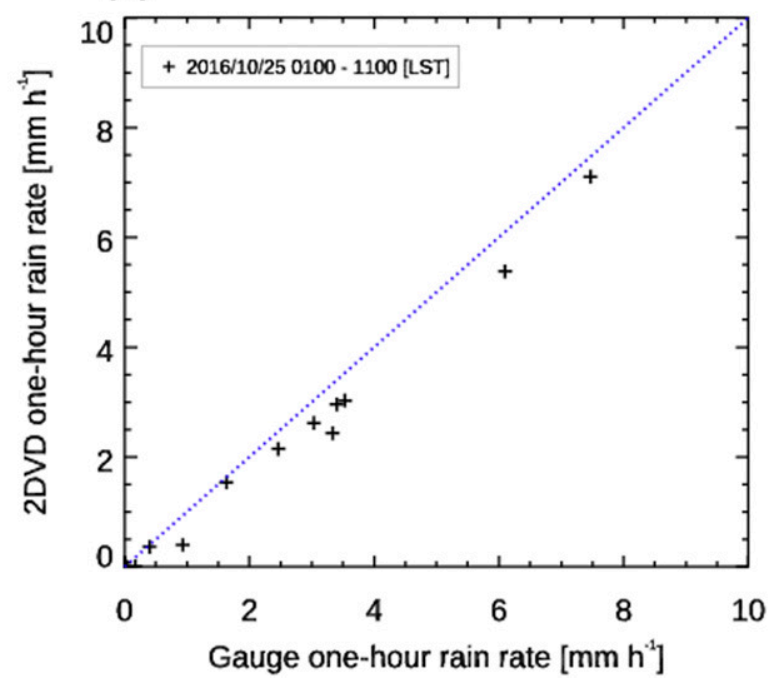

FIG. 4. Time series of (a),(c) accumulated rainfall and (b),(d) one-hour rain rates obtained from the rain gauge and estimated from the 2DVD. (a),(b) 27 Oct 2015 and (c),(d) 25 Oct 2016.

\section{Methodology}

\section{a. $C-G$ DSD model}

The C-G DSD was modeled by a gamma distribution, as shown in Eq. (3), which consists of three DSD parameters, namely, $N_{o}, \mu$, and $\Lambda$ (Ulbrich 1983):

$$
N(D)=N_{o} D^{\mu} \exp (-\Lambda \mathrm{D})
$$

where $N_{o}\left(\mathrm{~mm}^{-(1-\mu)} \mathrm{m}^{-3}\right)$ is a number concentration parameter; $\mu$ is a shape parameter; and $\Lambda\left(\mathrm{mm}^{-1}\right)$ is a slope parameter. The three DSD parameters can be calculated from the 2DVD data using the moment method. Assuming untruncated DSD, the integration of most DSD moment $\left(M_{n}\right)$ calculations is performed from 0 to infinite size range:

$$
\begin{aligned}
M_{n} & =\int_{0}^{\infty} D^{n} N(D) d D, \\
& =N_{o} \Lambda^{-(\mu+n+1)} \Gamma(\mu+n+1) \quad\left(\mathrm{mm}^{n} \mathrm{~m}^{-3}\right) .
\end{aligned}
$$

The three DSD parameters can be solved from the second, fourth, and sixth moments (Ulbrich and Atlas 1998), To eliminate $\Lambda$ and find the $\mu$, a ratio $(\eta)$ is defined [Eq. (5)] and DSD parameters are assumed according to Eqs. (6)-(8):

$$
\begin{aligned}
& \eta=\frac{\left(M_{4}\right)^{2}}{M_{2} M_{6}}=\frac{(\mu+3)(\mu+4)}{(\mu+5)(\mu+6)}, \\
& \mu=\frac{(7-11 \eta)-\left(\eta^{2}+14 \eta+1\right)^{1 / 2}}{2(\eta-1)},
\end{aligned}
$$


TABLE 1. Specifications for the S-band dual-polarization radar at the Yong-In Testbed site.

\begin{tabular}{lc}
\hline \hline \multicolumn{1}{c}{ Parameters } & Characteristics \\
\hline Variables & $Z_{H}, V_{r}, \mathrm{SW}, Z_{\mathrm{DR}}, \Phi_{\mathrm{DP}}, K_{\mathrm{DP}}, \rho_{\mathrm{hv}}$ \\
Altitude of radar antenna & $473.03 \mathrm{~m}$ \\
Transmitter type & Klystron \\
Transmitter peak power & $850 \mathrm{~kW}$ \\
Beamwidth of radar & $0.94^{\circ}$ \\
Pulse width & $2.0 \mu \mathrm{s}$ \\
Frequency & $2.879 \mathrm{MHz}(\mathrm{S}$ band $)$ \\
Observation range & $240 \mathrm{~km}$ \\
Gate size & $250 \mathrm{~m}$ \\
Elevations 27 Oct 2015 & $0.19^{\circ}, 0.61^{\circ}, 1.13^{\circ}, 1.85^{\circ}, 2.81^{\circ}, 4.22^{\circ}$, \\
& $6.22^{\circ}, 9.12^{\circ}, 13.27^{\circ}, 19.06^{\circ}, 80.0^{\circ}$ \\
& $0.19^{\circ}, 0.48^{\circ}, 0.83^{\circ}, 1.23^{\circ}, 1.75^{\circ}, 2.38^{\circ}$, \\
& $3.20^{\circ}, 5.63^{\circ}, 7.41^{\circ}$ \\
\hline
\end{tabular}

$$
\begin{aligned}
\Lambda & =\left[\frac{(4+\mu)(3+\mu) M_{2}}{M_{4}}\right]^{1 / 2}, \\
N_{0} & =\frac{M_{2} \Lambda^{(\mu+3)}}{\Gamma(\mu+3)}
\end{aligned}
$$

where $\Gamma$ is the complete gamma function, and $\mu$ and $\Lambda$ are parameters that represent the spectrum and size of the raindrop, respectively.

The actual raindrop distribution is observed within a finite size range $\left(D_{\min }, D_{\max }\right)$. Therefore, Eq. (2) is only applicable to untruncated DSD since it integrated from zero to infinity. For a gamma distribution with a truncated size range, the statistical moments are calculated as

$$
\begin{aligned}
M_{n}= & \int_{D_{\min }}^{D_{\max }} D^{n} N(D) d D \\
= & N_{0} \Lambda^{-(\mu+n+1)}\left[\gamma\left(\mu+n+1, \Lambda D_{\max }\right)\right. \\
& \left.-\gamma\left(\mu+n+1, \Lambda D_{\text {min }}\right)\right],
\end{aligned}
$$

where $\gamma(\ldots)$ is an incomplete gamma function, and $D_{\min }$ and $D_{\max }$ are 0.1 and $8 \mathrm{~mm}$ for 2DVD data. Overestimating DSD parameters can be minimized when appropriate truncated moments are used (Vivekanandan et al. 2004). Using the truncated moments shown in Eq. (9), moments consistent with truncation can be calculated, and then the corresponding expressions for DSD parameters can be derived as follows:

$$
\eta=\frac{\left[\gamma\left(\mu+5, \Lambda D_{\max }\right)-\gamma\left(\mu+5, \Lambda D_{\min }\right)\right]^{2}}{\gamma\left(\mu+3, \Lambda D_{\max }\right) \gamma\left(\mu+7, \Lambda D_{\max }\right)-\gamma\left(\mu+3, \Lambda D_{\min }\right) \gamma\left(\mu+7, \Lambda D_{\min }\right)},
$$

$$
\Lambda=\left\{\frac{D^{2}\left[\gamma\left(\mu+5, \Lambda D_{\max }\right)-\gamma\left(\mu+5, \Lambda D_{\min }\right)\right]}{D^{4}\left[\gamma\left(\mu+3, \Lambda D_{\max }\right)-\gamma\left(\mu+3, \Lambda D_{\min }\right)\right]}\right\}^{0.5} .
$$

Equations (10) and (11) constitute joint equations for $\mu$ and $\Lambda$ for the truncated moments, and an iterative approach is necessary to solve $\mu$ and $\Lambda$. The detailed procedure was as follows:

(i) Estimate the initial $\mu$ and $\Lambda$ values from Eqs. (5)-(7).

(ii) Compare the $\eta$ calculated in Eq. (10) with the measured-moment ratio $(\eta)$.

(iii) If the moment-two ratios are different, $\mu$ and $\Lambda$ are adjusted using Eq. (11) until $\eta$ from Eq. (10) converges to the measured moment ratio $(\eta)$.

\section{b. Shape-slope relationship}

To produce a $\mu-\Lambda$ relationship that reflects the rainfall characteristics of the Korean Peninsula and to analyze the truncation effect, $\mu$ versus $\Lambda$ was plotted for the 2DVD observations using untruncated and truncated methods. Figure 5 shows a scatterplot of the shape versus slope values; Fig. 5a was obtained from the untruncated DSDs and Fig. 5b from the truncated DSDs. When the truncation method was applied, the correlation increased slightly from 0.86 to 0.87 , but the scatter of the overestimated $\mu$ and $\Lambda$ was reduced slightly (Figs. 5a,b). Figures $5 \mathrm{c}$ and $5 \mathrm{~d}$ show the result of removing the low rain rate $\left(R \leq 5 \mathrm{~mm} \mathrm{~h}^{-1}\right)$ by applying thresholds to the untruncated and truncated DSDs, respectively. These scatterplots show less scatter, and the retrievals of $\mu$ and $\Lambda$ obtained using the truncated DSDs (Fig. 5d) show a stronger correlation than those retrieved using the untruncated DSDs (Fig. 5c).

Both $\mu$ and $\Lambda$ for a low rain rate $\left(R \leq 5 \mathrm{~mm} \mathrm{~h}^{-1}\right)$ are more scattered and broader than those for a high rain rate $\left(R>5 \mathrm{~mm} \mathrm{~h}^{-1}\right)$. Moreover, large values of $\mu(>15)$ and $\Lambda\left(>20 \mathrm{~mm}^{-1}\right)$ correspond to a low rain rate $(R<$ $\left.5 \mathrm{~mm} \mathrm{~h}^{-1}\right)$. Dual-polarization radar measurements are more sensitive to high rain rates than low rain rates. The $\mu-\Lambda$ relationship was derived as a polynomial function [Eq. (12)] from the filtered $\mu$ and $\Lambda$ parameters in Fig. $5 \mathrm{~d}$ (Zhang et al. 2001): 

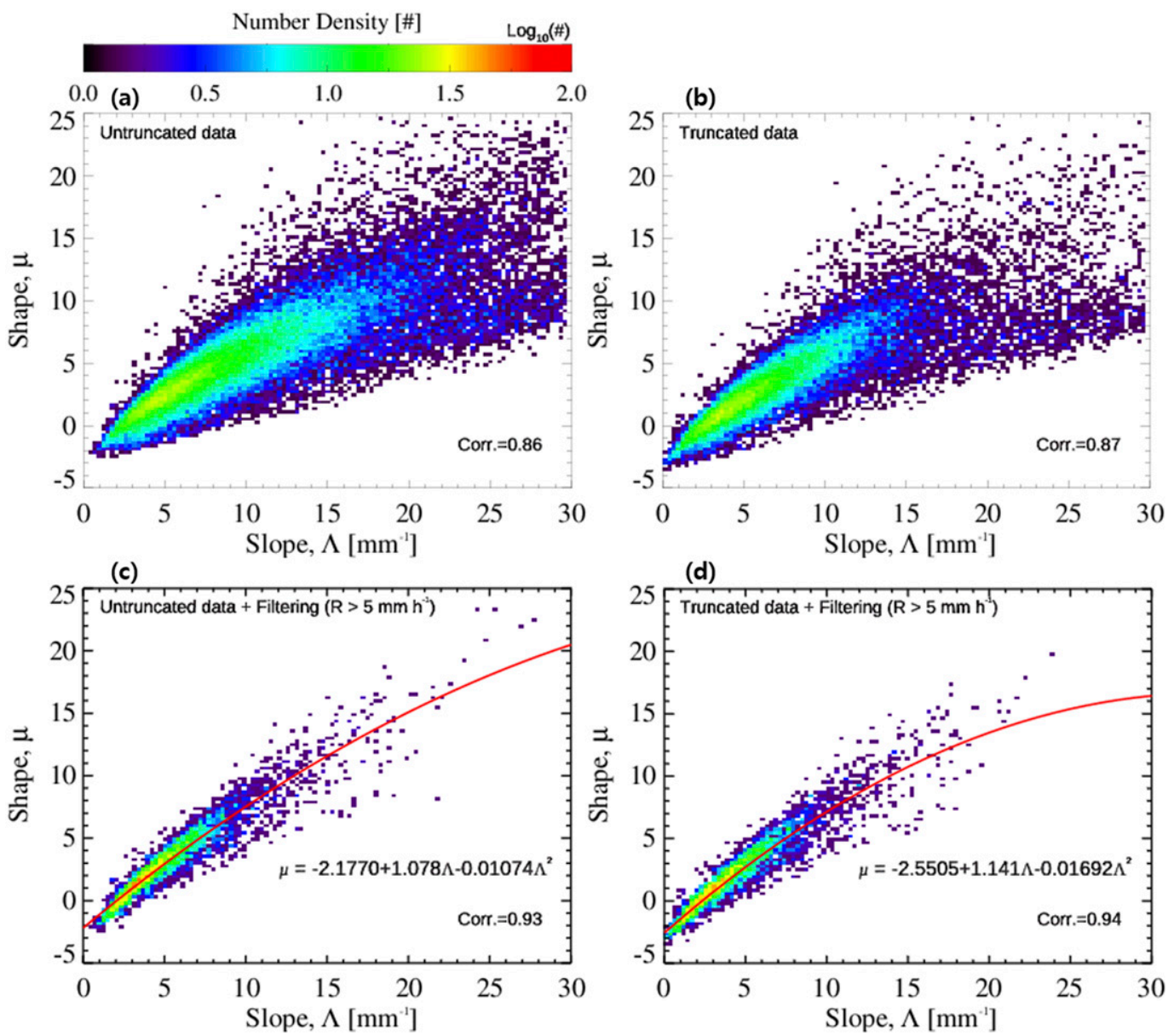

FIG. 5. Scatterplots of shape $(\mu)$ vs slope $(\Lambda)$ obtained from 2DVD observations: (a) Untruncated DSDs; (b) truncated DSDs; (c) as in (a), but that only measured DSDs where $R>5 \mathrm{~mm} \mathrm{~h}^{-1}$ are included; and (d) as in (b), but that only DSDs where $R>5 \mathrm{~mm} \mathrm{~h}^{-1}$ are included. The red line denotes the $\mu-\Lambda$ relation derived from (c) and (d) 2DVD observations.

$$
\begin{aligned}
\mu= & -2.551+1.141 \Lambda \\
& -0.01692 \Lambda^{2} \quad\left(0.1 \leq \Lambda<20 \mathrm{~mm}^{-1}\right) .
\end{aligned}
$$

Equation (12) applies only for the range $0.1 \leq \Lambda<$ $20 \mathrm{~mm}^{-1}$ because larger $\Lambda$ values $\left(>20 \mathrm{~mm}^{-1}\right)$ are related to measurement errors rather than storm physics (Zhang et al. 2003).

The $\mu-\Lambda$ relationship allows gamma DSD parameter $\left(N_{o}, \mu, \Lambda\right)$ retrieval from the $Z_{H}$ and $Z_{\mathrm{DR}}$ of dualpolarization measurements. The $\mu-\Lambda$ relationship is an important factor however, as the $\mu-\Lambda$ relationship derived from the 2DVD data contains errors, such as moment and fitting errors, and verification is required. The $D_{m}$ and $\sigma_{m}$ parameters were used to verify the new $\mu-\Lambda$ relationship. This can be calculated directly from 2DVD measurements and is independent of sorting and fitting procedures (Cao et al. 2008). The $D_{m}$ and $\sigma_{m}$ parameters representing the drop size are related to the $\mu$ and $\Lambda$ parameters and calculated using Eqs. (13a) and (13b). The $D_{m}$ equals the ratio of the fourth to the third moment of size distribution:

$$
\begin{aligned}
D_{m} & =\frac{M_{4}}{M_{3}}(\mathrm{~mm}), \\
\sigma_{m} & =\left[\frac{\int\left(D-D_{m}\right)^{2} D^{3} N(D) d D}{\int D^{3} N(D) d D}\right]^{0.5} .
\end{aligned}
$$

Figure 6a shows the scatterplot of calculated $D_{m}$ and $\sigma_{m}$ parameters from the observed DSDs over $43174 \mathrm{~min}$. The black solid line is the $\sigma_{m}-D_{m}$ relationship [Eq. (14)], which was calculated from gamma DSDs with the $\mu-\Lambda$ relationship constrained using Eq. (12). The red dashed line denotes $D_{m}$ and $\sigma_{m}$ as calculated from the observed DSDs (Williams et al. 2014); 

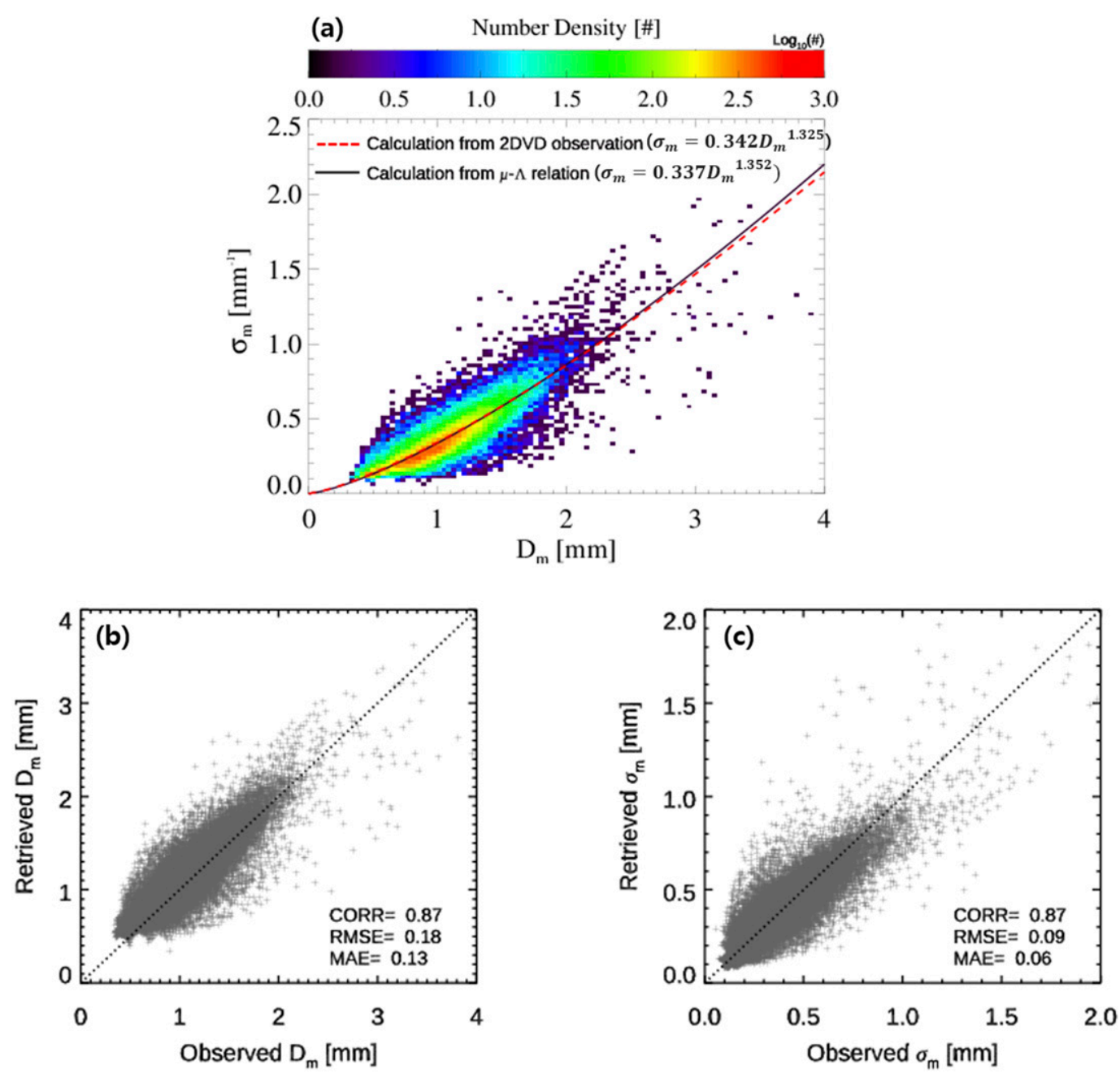

FIG. 6. (a) Scatterplot of $D_{m}$ vs $\sigma_{m}$. The color scale in (a) indicates that $D_{m}$ vs $\sigma_{m}$ is calculated from observed DSDs of $43174 \mathrm{~min}$. The black solid line denotes $D_{m}$ and $\sigma_{m}$ calculated from gamma DSDs with $\mu-\Lambda$ constrained by Eq. (9), and the red dashed line denotes $D_{m}$ and $\sigma_{m}$ calculated from observed DSDs; (b) one-to-one plot of retrieved $D_{m}$ vs observed $D_{m}$; and (c) as in (b), but for retrieved and observed $\sigma_{m}$.

$$
\sigma_{m}=0.337 D_{m}^{1.352}
$$

If the derived $\mu-\Lambda$ relationship represents the rain physics, the $\mu-\Lambda$ and $\sigma_{m}-D_{m}$ relationships should be consistent with the scatterplot of calculated $D_{m}$ and $\sigma_{m}$ from the 2DVD measurements. The correlation coefficient (Corr.), root-mean-square error (RMSE), and mean absolute error (MAE) of Eq. (15) were used to examine the goodness of fit of the $\mu-\Lambda$ relationship:

$$
\begin{aligned}
\text { Corr. } & =\frac{1}{N-1} \frac{\sum\left[(X-\bar{X})\left(X_{e}-\overline{X_{e}}\right)\right]}{\sqrt{\operatorname{Var}(X) \operatorname{Var}\left(X_{e}\right)}}, \\
\operatorname{RMSE} & =\left[\frac{1}{N} \sum\left(X-X_{e}\right)^{2}\right]^{1 / 2}\left(\mathrm{~mm} \mathrm{~h}^{-1}\right),
\end{aligned}
$$

$$
\text { MAE }=\frac{1}{N} \sum\left|X-X_{e}\right| \quad\left(\mathrm{mm} \mathrm{h}^{-1}\right),
$$

where $X$ and $X_{e}$ are the observed and retrieved $D_{m}$ and $\sigma_{m}$ parameters, respectively; and $N$ is the number of comparisons. One-to-one plots of observed and retrieved $D_{m}$ and $\sigma_{m}$ are shown in Figs. $6 \mathrm{~b}$ and $6 \mathrm{c}$. Both parameters showed a Corr. = 0.87 and low RMSE values of 0.18 and $0.09 \mathrm{~mm}$, respectively.

The newly derived $\mu-\Lambda$ relationship was compared with existing $\mu-\Lambda$ relationships for Florida and Oklahoma (Table 2). The $\mu-\Lambda$ relationship was then applied to the C-G DSD model, which was used to retrieve the rain DSD parameters from the polarization radar. 
TABLE 2. Different shape and slope relationships for different geographical locations.

\begin{tabular}{|c|c|c|c|}
\hline & Reference & Measurement & $\mu-\Lambda$ relationship \\
\hline 1 & Zhang et al. (2001) & Florida & $\begin{aligned} \mu= & -1.957+1.213 \Lambda \\
& -0.016 \Lambda^{2}\end{aligned}$ \\
\hline 2 & Cao et al. (2008) & Oklahoma & $\begin{aligned} \mu= & -1.718+0.902 \Lambda \\
& -0.0201 \Lambda^{2}\end{aligned}$ \\
\hline 3 & $\begin{array}{l}\text { New relationship } \\
\quad(\text { experimental fit) }\end{array}$ & Jincheon & $\begin{aligned} \mu= & -2.551+1.141 \Lambda \\
& -0.01692 \Lambda^{2}\end{aligned}$ \\
\hline
\end{tabular}

\section{c. DSD parameter retrievals}

The $Z_{H}$ and $Z_{\mathrm{DR}}$ of calibrated polarization radar measurements and a suitable DSD model are required to retrieve rain microphysical parameters. The calibration bias of radar $Z_{H}$ was calculated using the selfconsistency constraint between $Z_{H}$ and $K_{\mathrm{DP}}$. First, the rain region was selected to avoid ground echoes and brightband contamination. Second, $K_{\mathrm{DP}}$ was calculated at the precipitation region from the observed $Z_{H}$ using the $Z_{H}$ and $K_{\mathrm{DP}}$ relationship. Third, $\Phi_{\mathrm{DP} \text { cal }}$ was calculated by integrating the calculated $K_{\mathrm{DP}}$ along the ray and $\Phi_{\mathrm{DP} \text { obs }}$ was determined in the same ray. Finally, the calibration bias was estimated by comparing $\Phi_{\mathrm{DP}_{-} \text {cal }}$ and $\Phi_{\text {DP_obs }}$ (Goddard et al. 1994; Lee and Zawadzki 2006). The $Z_{\mathrm{DR}}$ calibration bias was calculated assuming that raindrops are azimuthally symmetric (i.e., $Z_{\mathrm{DR}}=0 \mathrm{~dB}$ ) in vertical pointing measurement (Gorgucci et al. 1999).

To select the appropriate DSD model, the exponential DSD model was used with the C-G DSD model based on the new $\mu-\Lambda$ relationship. The retrieved DSD parameters were then evaluated through a comparison with the 2DVD measurement. Figure 7 describes the process of retrieving the rain microphysical parameters from the dual-polarization radar data. The DSD retrieval procedure aimed to find a DSD whose 2DVD calculated radar variables matched the radar observations. This meant that the calculation of radar variables was as important a factor in the DSD retrieval as the connection between the DSD and the radar variables. The procedure of C-G DSD retrieval was described in section 6.4.2. by Zhang (2016) and a brief process is shown below:

(i) $\mu$ and $\Lambda$ were derived from the measured $Z_{\mathrm{DR}}$, using an iteration method between the $Z_{\mathrm{DR}}$ definition $\left(Z_{\mathrm{DR}}=Z_{H} / Z_{V}\right)$ and the $\mu-\Lambda$ relationship [Eq. (12)];

(ii) $N_{o}$ was derived from the $Z_{H}$ definition [Eq. (16)] and $\mu$ and $\Lambda$ were calculated [Eq. (6.19) by Zhang 2016];

(iii) the rain microphysical parameters were calculated;

(iv) the 2DVD measurements were used for verification;

$$
\begin{aligned}
Z_{H, V}= & \frac{4 \lambda^{4}}{\pi^{4}\left|K_{w}\right|^{2}} N_{o} \\
& \times \int_{0}^{D_{\max }} D^{\mu} \exp (-\Lambda D)\left|f_{a, b}(\pi)\right|^{2} d D \quad\left(\mathrm{~mm}^{6} \mathrm{~m}^{-3}\right)
\end{aligned}
$$

where $\lambda$ is the radar wavelength $(\lambda=10.7 \mathrm{~cm}) ; K_{w}$ is the dielectric factor for water $(=0.93)$, and $f_{a}(\pi)$ and $f_{b}(\pi)$ are complex backscattering amplitudes for polarization along the major and minor axes, respectively. The functions $f_{a}(\pi)$ and $f_{b}(\pi)$ were calculated at the S band of the $10.7 \mathrm{~cm}$ wavelength by using the mean raindrop axis-ratio relationship of Brandes et al. (2002) and the T-matrix (transition) method.

The rain microphysical parameters retrieved were the total number concentration $\left(N_{t}\right)$, mass-weighted mean diameter $\left(D_{m}\right)$, water content $(W)$, and rain rate $(R)$. The parameters are defined in section 2.1.1.1. by Zhang (2016). These rain microphysical parameters were

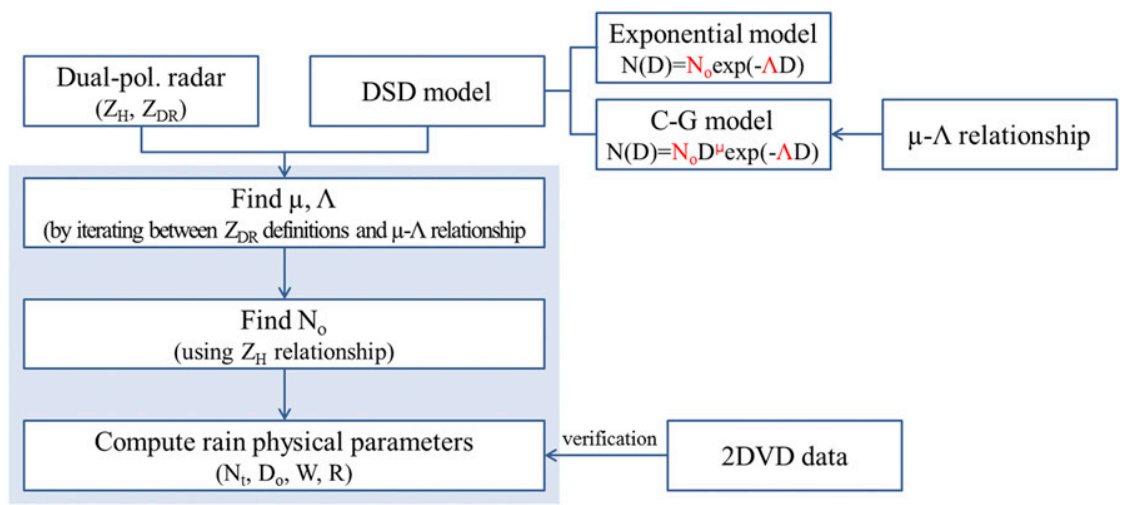

FIG. 7. Flowchart of rain microphysical parameters retrieval from dual-polarization radar measurements using the constrained-gamma model. 
verified via a quantitative comparison with rain parameters calculated directly from the 2DVD measurements. To quantitatively compare the radar and 2DVD rain microphysical parameters, a second elevation angle was used for which the height difference between the radar and 2DVD was approximately $0.7 \mathrm{~km}$. The 2DVD data were averaged over two observation times centered on the YIT radar observation time. This was because rain microphysical parameters retrieved from the $Z_{H}$ and $Z_{\mathrm{DR}}$ of the polarization radar are 5-min observations, whereas rain microphysical parameters calculated from the 2DVD measurement are 1-min observations.

\section{Results}

\section{a. Comparison of shape-slope relations}

Figure 8 shows a comparison of $\mu-\Lambda$ relationships derived from the 2DVD observation data for various geographical locations. The dotted and dashed lines correspond to Florida (Zhang et al. 2001) and Oklahoma (Cao et al. 2008), respectively, and the solid line is the mean curve fitted to the 2DVD data at Jincheon. When comparing the three $\mu-\Lambda$ relations, the trend of the $\mu-\Lambda$ relationship derived for the Korean Peninsula is similar to that of Florida. However, both of these $\mu-\Lambda$ relationships differ from that of Oklahoma (Cao et al. 2008), as the value of $\Lambda$ increases. For the same $\Lambda$ value, the $\mu$ values for Florida and the Korean Peninsula are larger than for Oklahoma.

The $\mu-\Lambda$ relationships derived at all three regions used rainfall observation data from 2DVD, but the difference in derived $\mu-\Lambda$ relationships is mainly due to a different fitting procedure used to fit the DSD data. In Zhang et al. (2001), the DSDs were fitted using moment fit and the Florida $\mu-\Lambda$ relationships was derived from the data with a simple threshold of $R>5 \mathrm{~mm} \mathrm{~h}^{-1}$ to filter the data. The $\mu-\Lambda$ relationships in Cao et al. (2008) was derived from the truncating moment fitting processed with a sorting and averaging method based on two parameters (SATP). SATP method reduces the effects of light rain events and minimizes sampling errors. The new $\mu-\Lambda$ relationships was derived from the DSDs data using truncated moment fit and a threshold of $R>5 \mathrm{~mm} \mathrm{~h}^{-1}$.

\section{b. Retrieval of rain DSD parameter}

\section{1) 27 OCTOBER 2015}

There was well-developed stratiform precipitation event influenced by a trough of low pressure. The averaged observation rainfall amount was approximately $18.2 \mathrm{~mm}$ between 0200 and $1000 \mathrm{KST}$ at Jincheon station. The $Z_{H}$ and $Z_{\mathrm{DR}}$ calibration biases for the YIT radar were -2.64 and $-0.28 \mathrm{~dB}$, respectively. The YIT

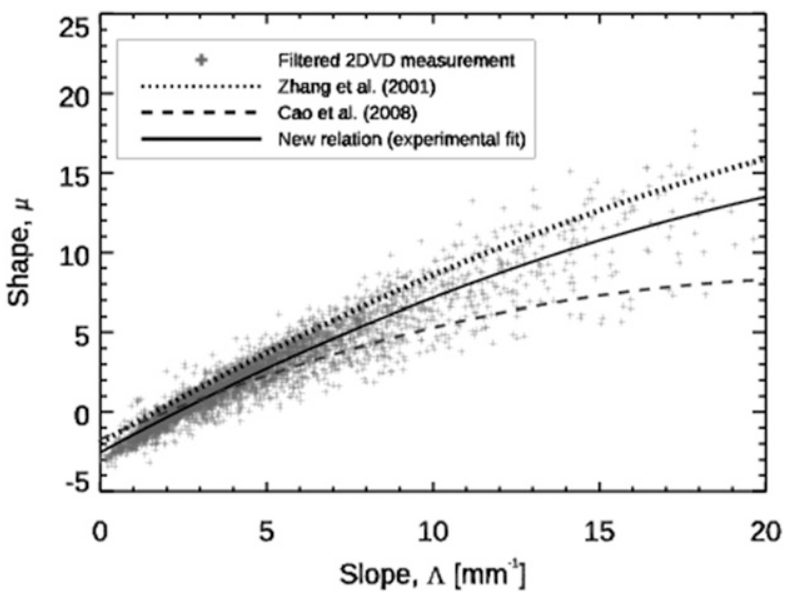

FIG. 8. Different shape $(\mu)$-slope $(\Lambda)$ relationships for different geographical areas. The dotted and dashed lines correspond to Florida (Zhang et al. 2001) and Oklahoma (Cao et al. 2008), respectively, and the solid line is the mean curve fitted to the 2DVD data at Jincheon.

radar $Z_{H}$ and $Z_{\mathrm{DR}}$ measurements were underestimated with respect to the simulated $Z_{H}$ and $Z_{\mathrm{DR}}$ values. Figure 9 shows the rain microphysics retrievals from the YIT radar measurements using the exponential DSD model and the C-G DSD model based on the new $\mu-\Lambda$ relationships. The calculations using the 2DVD measurements are also presented. In comparison with the 2DVD, the exponential DSD model overestimated $N_{t}, W$, and $R$ (Figs. 9a,c,d, respectively) and underestimated $D_{m}$ (Fig. 9b). In addition, the retrieval results based on the C-G DSD model showed a similar distribution to the rain microphysical parameters calculated from the 2DVD, while the retrieved parameters based on the exponential model showed the largest variation, particularly for $N_{t}$.

The simulated $Z_{H}$ and $Z_{\mathrm{DR}}$ from the 2DVD measurements were compared with the $Z_{H}$ and $Z_{\mathrm{DR}}$ of the YIT radar measurements simultaneously (Fig. 9e). The maximum observed values of $Z_{H}$ in sections $\mathrm{A}$ and $\mathrm{B}$ (0416 and 0721 KST, respectively) in Fig. 9 were 34 and $37 \mathrm{~dB} Z$, respectively, indicating a difference of $3 \mathrm{~dB}$. However, the $Z_{\mathrm{DR}}$ was approximately 3 times higher in section $\mathrm{B}\left(Z_{\mathrm{DR}} \approx 1.4 \mathrm{~dB}\right)$ than in section $\mathrm{A}\left(Z_{\mathrm{DR}} \approx\right.$ $0.5 \mathrm{~dB})$. The $D_{m}$ parameter in section B was also significantly greater (Fig. 9b). However, the $N_{t}, W$, and $R$ parameters had a higher value in section $A$ than in section $\mathrm{B}$. The maximum particle size of the DSD was approximately $2.5 \mathrm{~mm}$ in section A (0416 KST) but it was less than $3.5 \mathrm{~mm}$ in section B (0721 KST). In contrast, $N_{t}$ was higher in section A than in section B (Figs. 9a,g).

To understand the vertical structure of the precipitation system, the QVP time series data of $9.12^{\circ}$ PPI were analyzed (Fig. 10). At the beginning of the precipitation event, at approximately $0200 \mathrm{KST}$, a low precipitation 

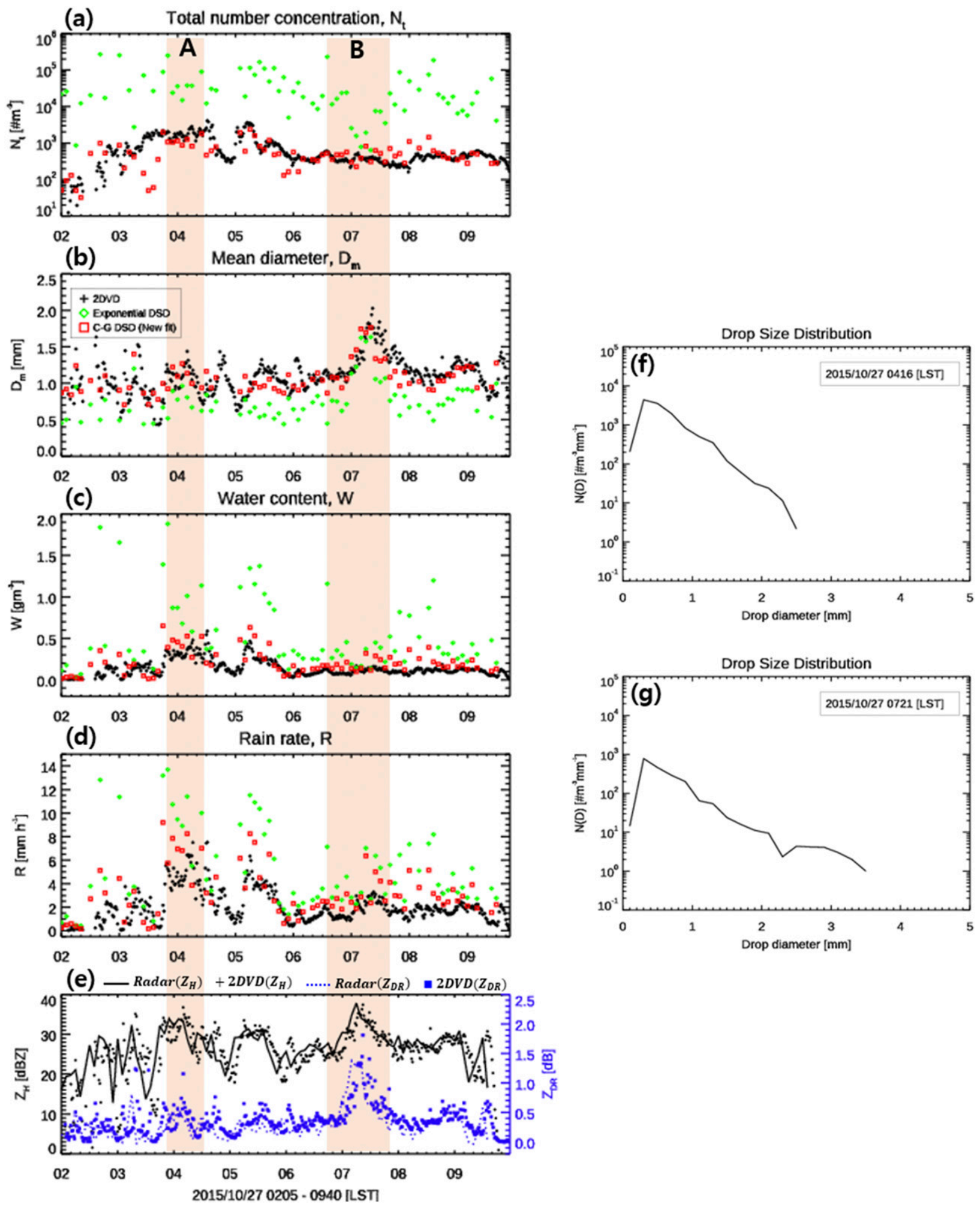

FIG. 9. Time series comparison of rain physical parameter retrievals: (a) total number concentration $N_{t}$; (b) mass-weighted mean diameter $D_{m}$; (c) water content $W$; (d) rain rate $R$; and (e) reflectivity and differential reflectivity from the Yong-in dual-polarization radar measurements and 2DVD on 27 Oct 2015; and drop size distribution from 2DVD at (f) 0416 LST and (g) 0721 LST. Results are shown for 2DVD measurements and retrieved values using exponential and constrained gamma (C-G) DSD models based on the new $\mu-\Lambda$ relationship. 


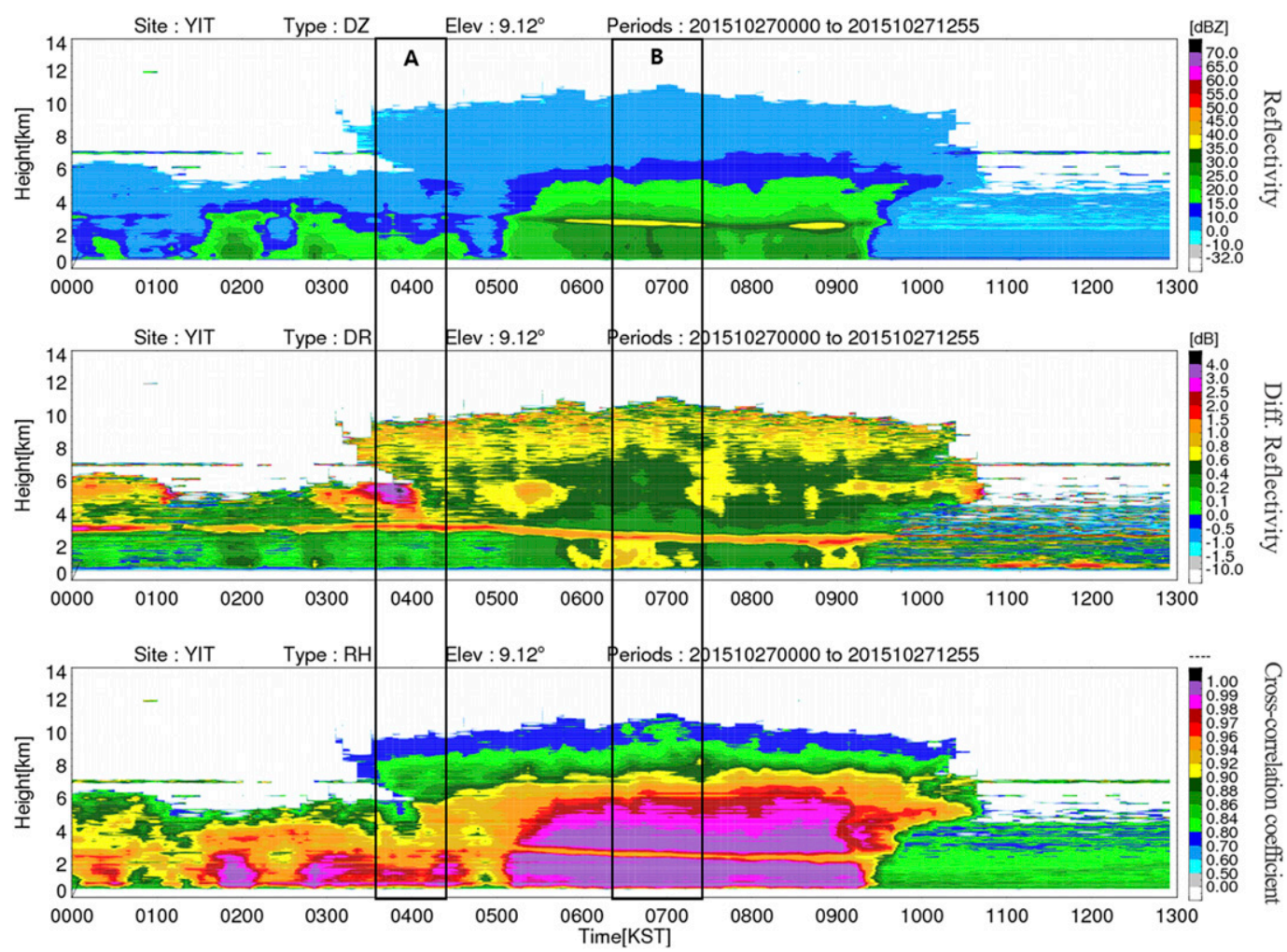

FIG. 10. Time series of quasi-vertical profile (QVP) images of $9.12^{\circ}$ PPI: (a) reflectivity, (b) differential reflectivity, and (c) cross-correlation coefficient from Yong-in dual-polarization radar measurements on 27 Oct 2015.

system of less than $6 \mathrm{~km}$ appeared vertically. After $0340 \mathrm{KST}$, the precipitation system developed to a height of approximately $10 \mathrm{~km}$. The bright band was clearly detected at a height of approximately $3 \mathrm{~km}$. However, the bright band gradually decreased over time to approximately $2.5 \mathrm{~km}$. This is due to low-level cold advection by northerly winds associated with the surface low and behind the cold front. After $0530 \mathrm{KST}, Z_{H}$ and $Z_{\mathrm{DR}}$ increased as the brightband height decreased. Notably, the increases in $Z_{H}$ and $Z_{\mathrm{DR}}$ between 0630 and $0730 \mathrm{KST}$ were substantial. In period A, vertical structure development is weaker than in period $\mathrm{B}$, but it had larger $N_{t}, W$, and $R$ parameters, implying that many more small drops in that period that contributed to the $Z_{H}$, while in period $\mathrm{B}$ there were fewer but larger drops contributing to $Z_{H}$ and $Z_{\mathrm{DR}}$ (as is illustrated in Figs. 9f,g). In addition, the collision-coalescence process, ice processes and aggregation can lead to growth of drops below the melting layer and contribute to the surface DSDs. Aggregation concentrates the condensate into large particles rather than adding mass to precipitation. Since $Z_{H}$ is proportional to particle size $\left(Z_{H} \approx D^{6}\right)$, aggregation leads to an increase in the radar echo (Lohmann et al. 2016). $Z_{\mathrm{DR}}$ grows more rapidly as the $Z_{H}$ increases because the shape of raindrops becomes more oblate as the particle size increases (Ryzhkov and Zrnić 1998).

The rain microphysical parameters retrieved in the two models were quantitatively compared with the parameters calculated from the 2DVD data (Fig. 11). The accuracy of the retrieved rain microphysical parameters was better when the C-G DSD model was used than when the exponential DSD model was used. Specifically, when the C-G DSD model was based on the new $\mu-\Lambda$ relationship, the RMSE values for the $N_{t}, D_{m}, W$, and $R$ parameters were $0.97 \mathrm{~m}^{-3}, 0.18 \mathrm{~mm}, 0.12 \mathrm{~g} \mathrm{~m}^{-3}$, and $1.68 \mathrm{~mm} \mathrm{~h}^{-1}$, respectively, which were significantly lower than those of the exponential model $\left(3.98 \mathrm{~m}^{-3}\right.$, $0.44 \mathrm{~mm}, 0.57 \mathrm{~g} \mathrm{~m}^{-3}$ and $3.91 \mathrm{~mm} \mathrm{~h}^{-1}$, respectively). Of particular note is the fact that the $W$ and $R$ parameters for the condition $R>5 \mathrm{~mm} \mathrm{~h}^{-1}$ ( + red crosses) - which were widely scattered when the exponential DSD model was used-were concentrated when the new C-G DSD model was used.

\section{2) 25 OCTOBER 2016}

From 0100 to $0820 \mathrm{KST}$, a stratiform storm of less than $35 \mathrm{dBZ}$ passed over Jincheon station. Between approximately $0820 \mathrm{KST}$ and $0900 \mathrm{KST}$, a convective storm of up to $45 \mathrm{~dB} Z$ passed over the station (Fig. 12e). 
2DVD vs Exponential DSD
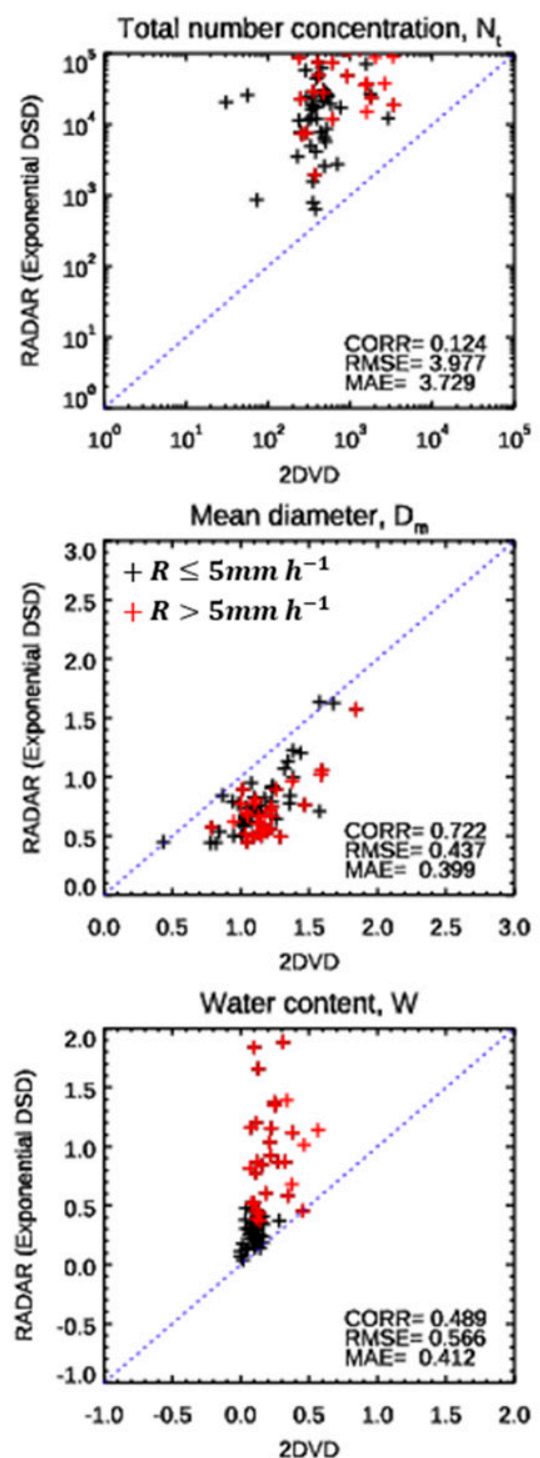

Rain rate, $R$

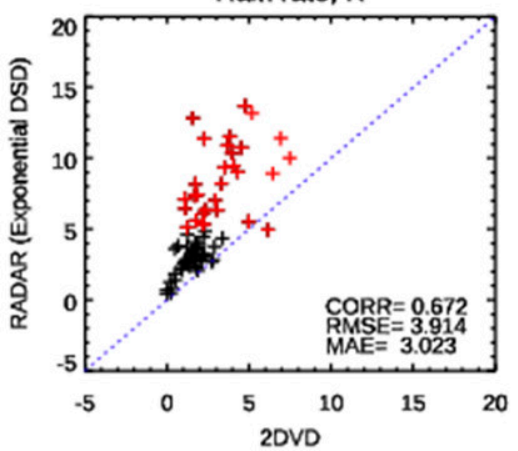

2DVD vs C-G DSD(new $\mu-\Lambda$ fit)

Total number concentration, $\mathrm{N}$

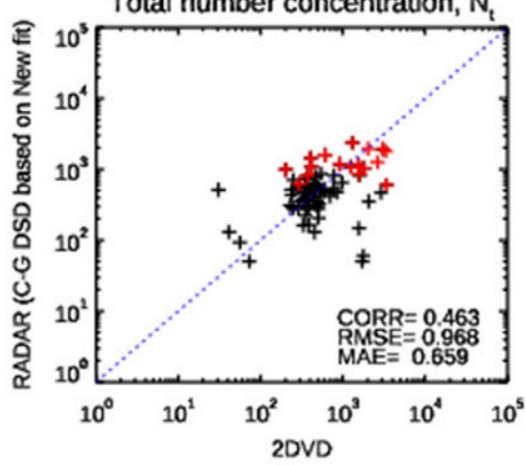

Mean diameter, $\mathrm{D}_{m}$

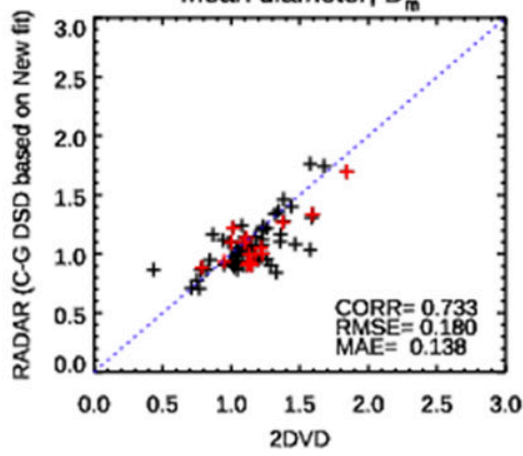

Water content, W

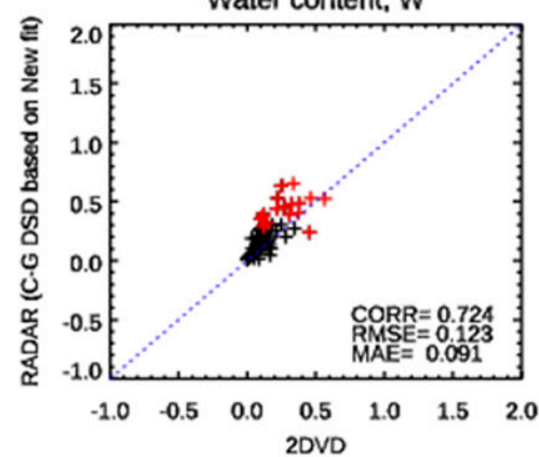

Rain rate, $R$

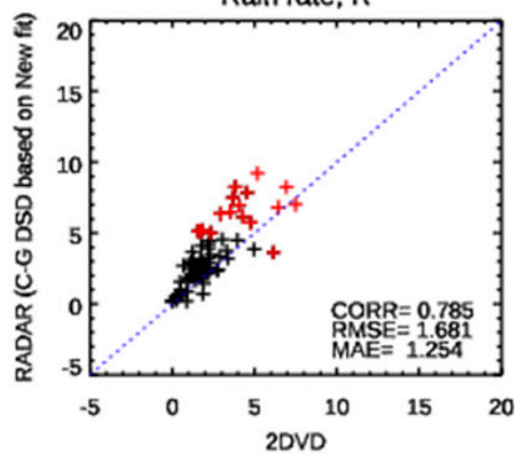

FIG. 11. Scatterplots of rain physical parameters (from top to bottom) $N_{t}, D_{m}, W$, and $R$ obtained using different DSD models and 2DVD measurements on 27 Oct 2015. (left) The exponential DSD and (right) the constrained gamma (C-G) DSD model (based on the new $\mu-\Lambda$ relationship) are shown. Black and red crosses represent $R \leq 5 \mathrm{~mm} \mathrm{~h}^{-1}$ and $R>5 \mathrm{~mm} \mathrm{~h}^{-1}$, respectively. 
(a)

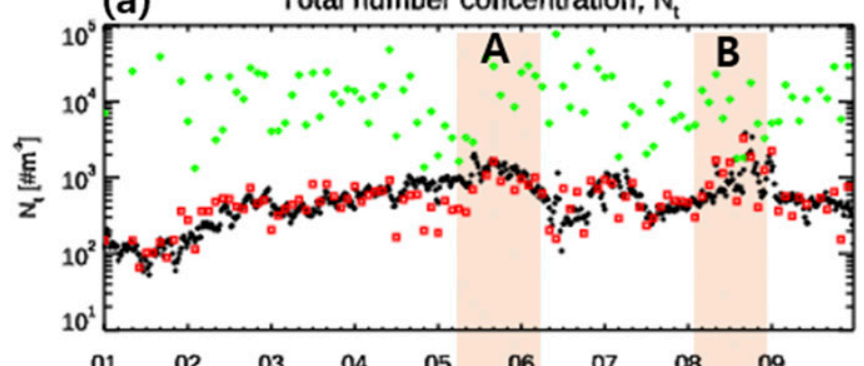

(b)
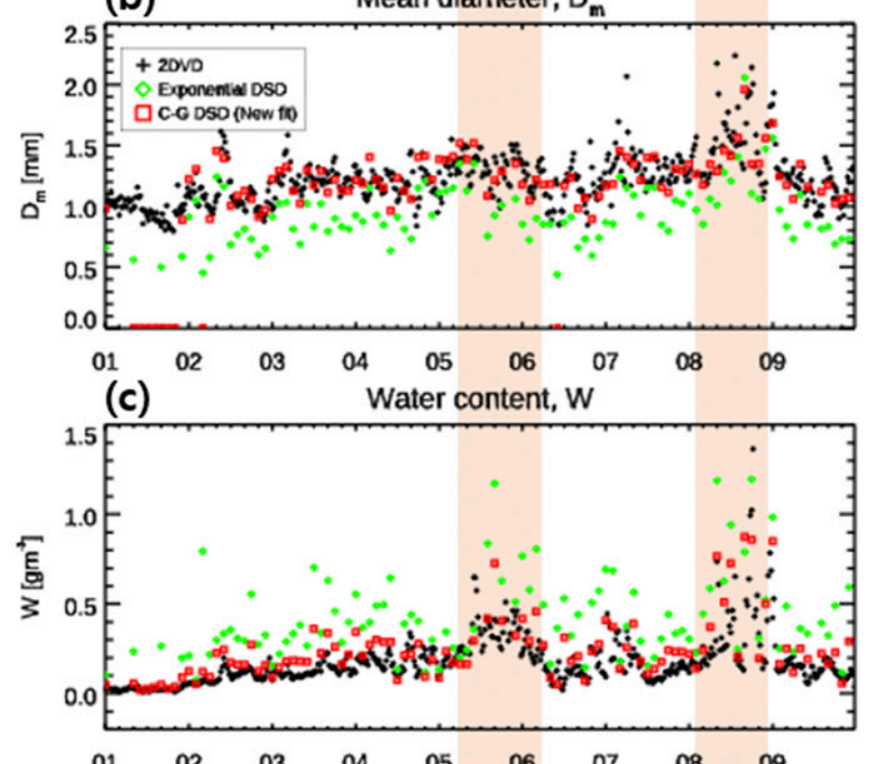

(d)

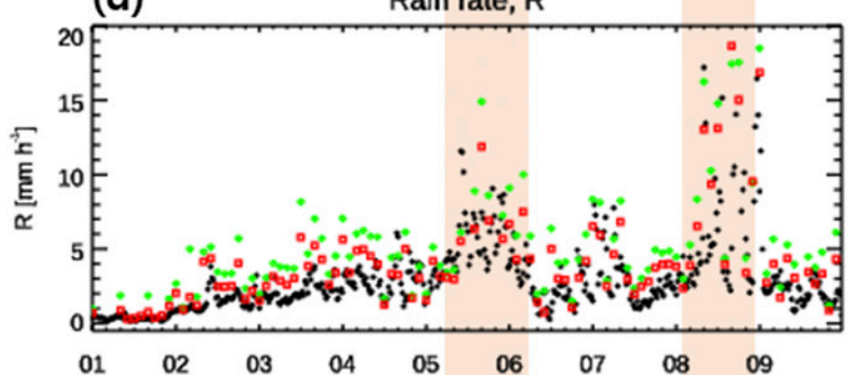

(e) $-\operatorname{Radar}\left(Z_{H}\right)+2 D V D\left(Z_{H}\right) \quad \ldots \ldots \cdot \operatorname{Radar}\left(Z_{D R}\right) \quad \boldsymbol{\|} 2 D V D\left(Z_{D R}\right)$

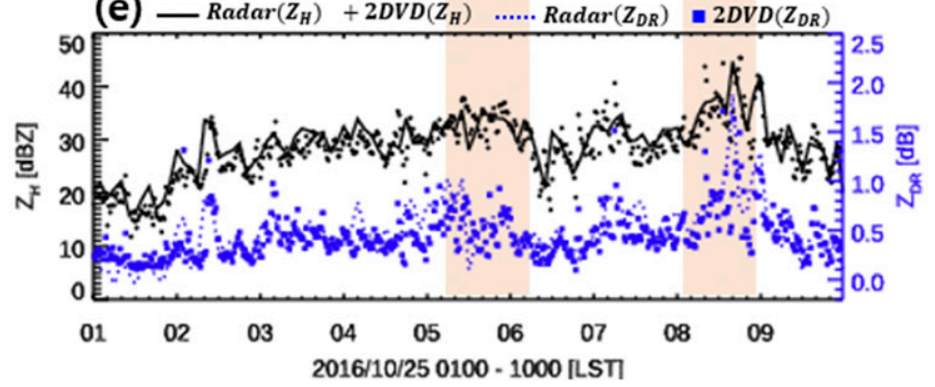

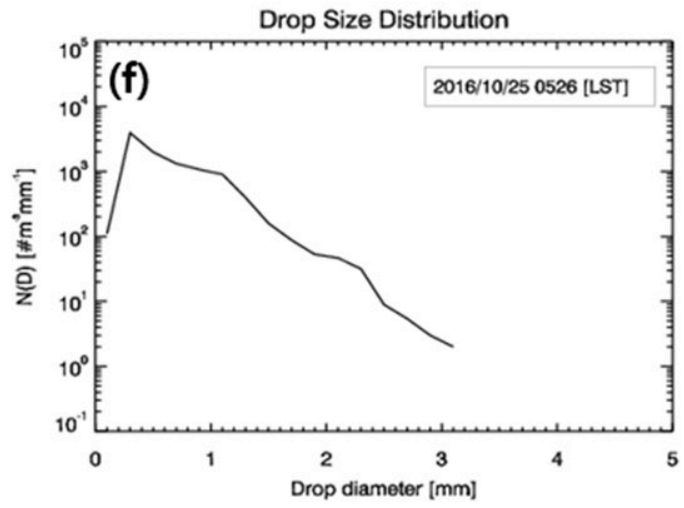

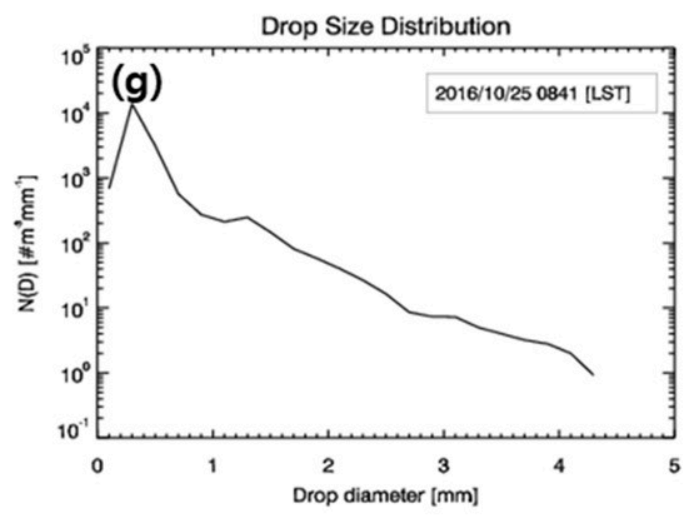

FIG. 12. As in Fig. 9, but for 25 Oct 2016 and with a drop size distribution from 2DVD at (f) 0526 LST and (g) 0841 LST. 


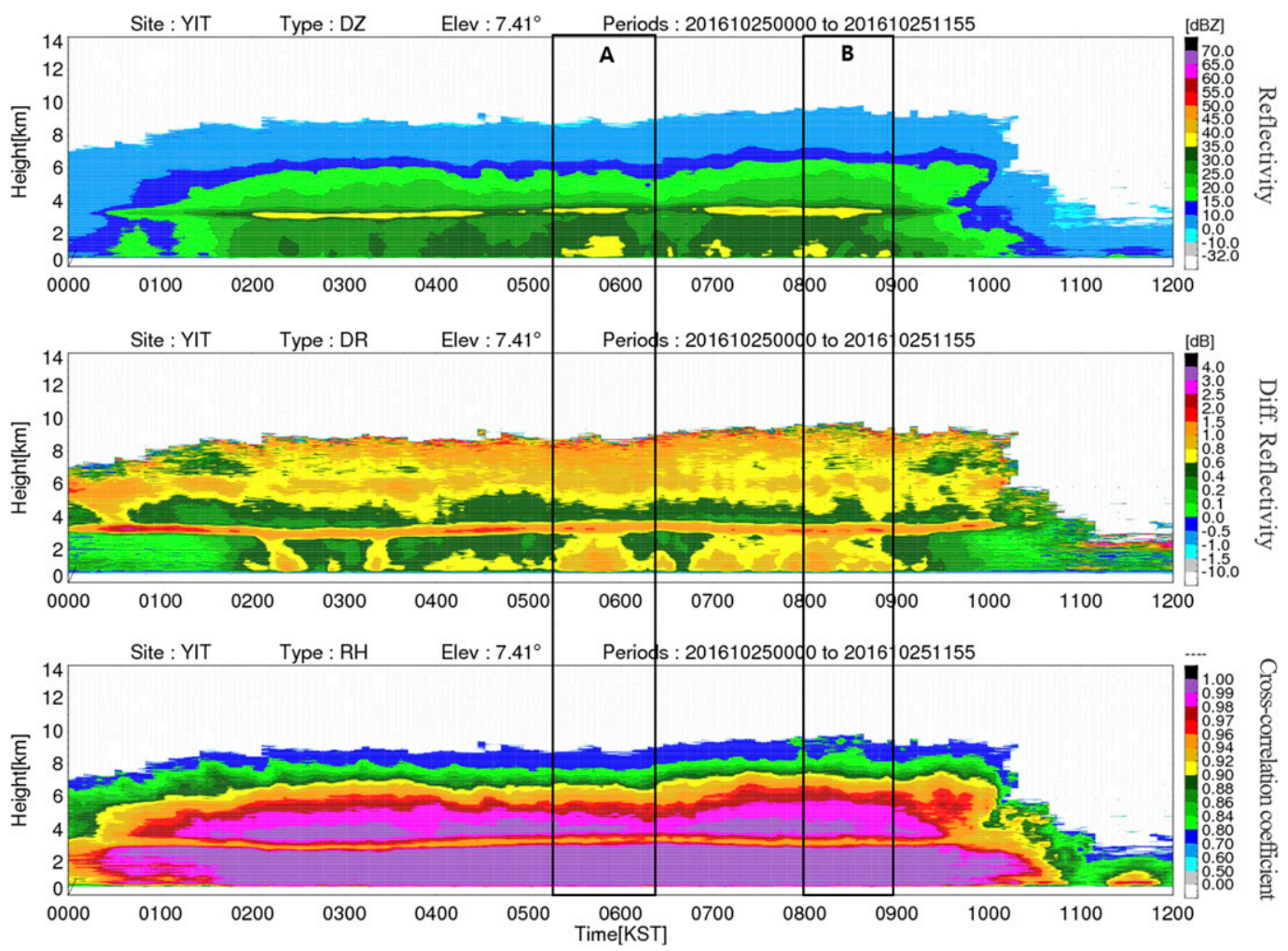

FIG. 13. As in Fig. 10, but for 25 Oct 2016.

The $Z_{H}$ and $Z_{\mathrm{DR}}$ calibration biases for the YIT radar were -3.51 and $0.23 \mathrm{~dB}$, respectively. The YIT $Z_{H}$ measurement was underestimated and $Z_{\mathrm{DR}}$ was overestimated. The rain microphysical data retrieved from the YIT radar based on the exponential DSD model were overestimated for the $N_{t}, W$, and $R$ parameters (Figs. 12a,c,d, respectively) and underestimated for the $D_{m}$ parameter (Fig. 12b) compared with those calculated from the 2DVD measurements. In addition, the exponential DSD model showed the largest variation among the DSD models.

The rain microphysical parameters increased in both sections A and B, and particularly in the latter. Between 0520 and $0540 \mathrm{KST}$, a strong precipitation system deviated from Jincheon station. The rain microphysical parameters and $Z_{H}$ and $Z_{\mathrm{DR}}$ values decreased for a period before increasing again. Figures $12 \mathrm{f}$ and $12 \mathrm{~g}$ show the DSD of section A (0526 KST) and B (0841 KST). The maximum particle size in section $B$ was $4.3 \mathrm{~mm}$ with a broader DSD than in section A $(3.1 \mathrm{~mm})$ and a higher $N_{t}$. Period B had higher rain rates and a larger contribution of large drops.

In the QVP time series data of $7.41^{\circ} \mathrm{PPI}$, the precipitation system had developed by up to approximately $8 \mathrm{~km}$ since the precipitation system approached from $0000 \mathrm{KST}$ onward. The bright band that appeared at approximately $3 \mathrm{~km}$ at $0000 \mathrm{KST}$ gradually decreased, but then increased gradually after $0400 \mathrm{KST} . Z_{H}$ and $Z_{\mathrm{DR}}$ also increased when the brightband height increased. In particular, $Z_{H}$ and $Z_{\mathrm{DR}}$ increased in section A and $\mathrm{B}$ below the brightband height (Fig. 13).

Based on the evaluation of the accuracy of the two DSD models, all rain microphysical parameters showed the highest Corr. values and lowest RMSE and MAE values when using the newly derived $\mu-\Lambda$ relationship. In particular, the Corr. and RMSE values for $N_{t}$ parameters were greatly improved from -0.06 to 0.74 and from 3.13 to $0.54 \mathrm{~m}^{-3}$ (Fig. 14), respectively.

\section{Conclusions}

In this study, a new $\mu-\Lambda$ relationship was derived using observed 2DVD data from 2014 to 2016 at Jincheon station, South Korea. Rain microphysical parameters were then retrieved from the YIT dual-polarization radar by applying the derived $\mu-\Lambda$ relationship. To reduce the 2DVD measurement errors, quality control was performed using the fall velocity relationship and rain gauge data, and DSDs were fitted using the truncated moment method to all the data points in valid range.

The $\mu$ and $\Lambda$ DSD parameters represented different raindrop shapes and sizes. The $\mu-\Lambda$ relationship was 
2DVD vs Exponential DSD
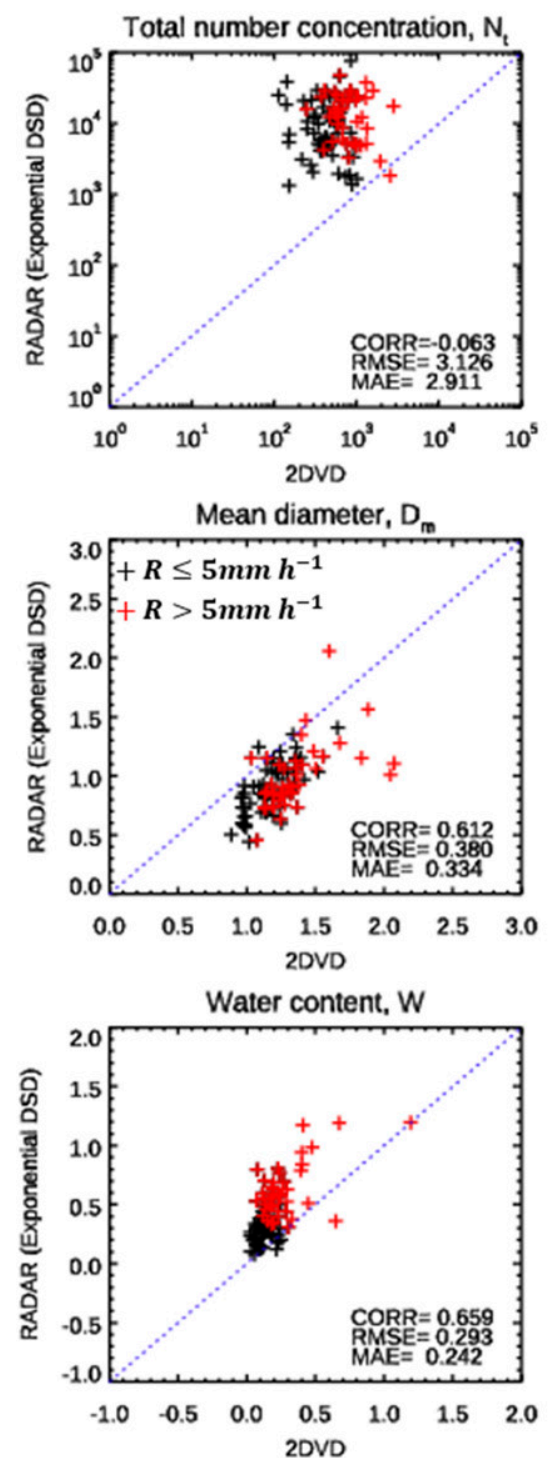

Rain rate, $R$

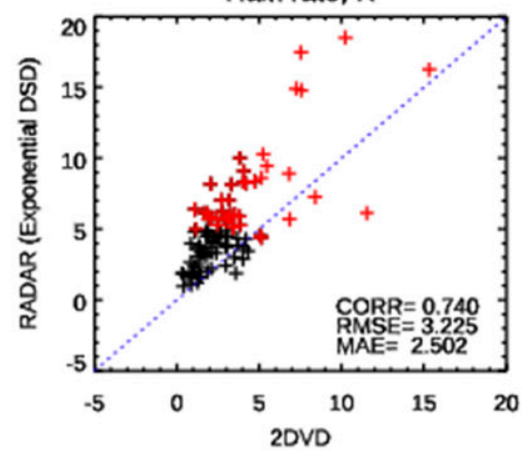

2DVD vs C-G DSD(new $\mu-\Lambda$ fit)
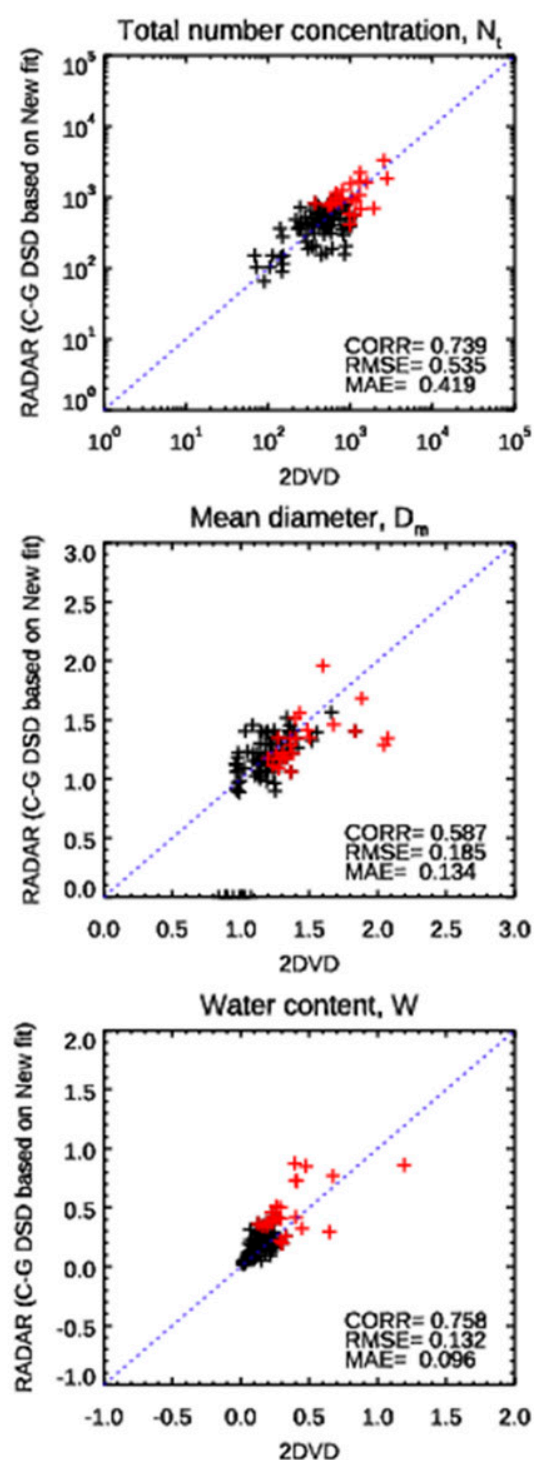

Rain rate, $R$

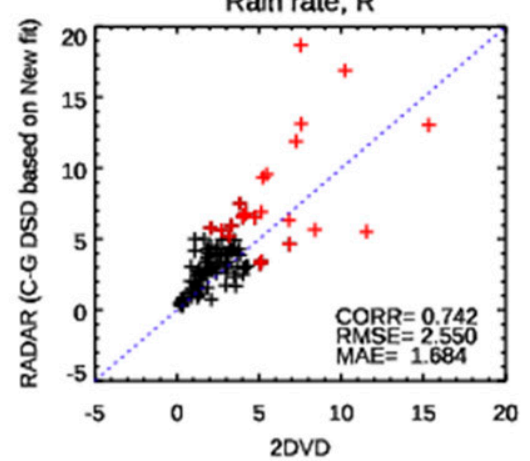

FIG. 14. As in Fig. 11, but for 25 Oct 2016. 
used as a constraint that allows DSDs to be retrieved using polarization radar. To increase the correlation between $\mu$ and $\Lambda$, truncation effects were considered and the data for low rain rates $\left(R<5 \mathrm{~mm} \mathrm{~h}^{-1}\right)$ were filtered to derive the $\mu-\Lambda$ relationship. The $D_{m}$ and $\sigma_{m}$ parameters, which were independent of particle sorting and fitting processes, were used to verify the derived $\mu-\Lambda$ relationship. The $D_{m}$ and $\sigma_{m}$ calculated from the 2DVD measurement showed a correlation of 0.87 using $D_{m}$ and $\sigma_{m}$ estimated from the $\mu-\Lambda$ relationship, and low RMSE (0.18 and $0.09 \mathrm{~mm})$ and MAE (0.13 and $0.06 \mathrm{~mm}$ ) values.

The derived $\mu-\Lambda$ relationship for the Korean Peninsula was compared with that of Florida (Zhang et al. 2001) and Oklahoma (Cao et al. 2008). The results showed similar distributions between the new $\mu-\Lambda$ relationship and Florida, whereas the new $\mu-\Lambda$ relationship with its increasing $\Lambda$ values different from Oklahoma. Differences in the derived relations can be inferred from differences in the fitting procedure, data selection, filtering and the geographical location of the observed data.

The $\mu-\Lambda$ relationship for the Korean Peninsula was used to retrieve rain microphysical parameters from the $Z_{H}$ and $Z_{\mathrm{DR}}$ values of YIT radar and compared the exponential and C-G DSD models to select the appropriate model. The QVP time series data were compared for the analysis of the vertical structure and microphysics of the precipitation system. The rain microphysical parameters calculated from the 2DVD data were also quantitatively compared.

The polarization radar retrieval-based C-G DSD model characterized rain microphysical parameters more accurately than the exponential DSD model. Furthermore, the C-G DSD model based on the newly derived $\mu-\Lambda$ relationship showed the best performance. These results suggest that the C-G DSD model expresses the DSD more naturally than the exponential DSD model when retrieving microphysical parameters using polarization radar. Moreover, the $\mu-\Lambda$ relationship used in the $\mathrm{C}-\mathrm{G}$ DSD model should better reflect the climate and precipitation characteristics of the Korean Peninsula.

Future work will consider the $K_{\mathrm{DP}}$ observation to improve the accuracy of DSD retrieval and the estimation of rain microphysical parameters. The retrieval algorithm will be tested in various precipitation systems, such as typhoons and the rainy season, and optimized for real-time application. These results can be beneficial for the microphysical analysis of other precipitation systems, for improved parameterization in NWP, and for data assimilation.

Acknowledgments. This research was supported by the "Development and application of cross governmental dual-pol radar harmonization (WRC-2013-A-1)" project of the Weather Radar Center, Korea Meteorological Administration.

\section{REFERENCES}

Atlas, D., R. C. Srivastava, and R. S. Sekkon, 1973: Doppler radar characteristics of precipitation at vertical incidence. Rev. Geophys., 2, 1-35, https://doi.org/10.1029/RG011i001p00001.

Brandes, E. A., G. Zhang, and J. Vivekanandan, 2002: Experiments in rainfall estimation with a polarimetric radar in a subtropical environment. J. Appl. Meteor., 41, 674-685, https://doi.org/ 10.1175/1520-0450(2002)041<0674:EIREWA > 2.0.CO;2.

,-- , and - , 2003: An evaluation of a drop distributionbased polarimetric radar rainfall estimator. J. Appl. Meteor., 42, 652-660, https://doi.org/10.1175/1520-0450(2003)042<0652: AEOADD $>2.0 . \mathrm{CO} ; 2$.

,-- , and,$- 2004 \mathrm{a}$ : Drop size distribution retrieval with polarimetric radar: Model and application. J. Appl. Meteor., 43, 461-475, https://doi.org/10.1175/1520-0450(2004)043<0461: DSDRWP $>2.0 . \mathrm{CO} ; 2$.

,-- , and,$- 2004 \mathrm{~b}$ : Comparison of polarimetric radar drop size distribution retrieval algorithms. J. Atmos. Oceanic Technol., 21, 584-598, https://doi.org/10.1175/1520-0426(2004)021<0584: COPRDS $>2.0$.CO;2.

Bringi, V. N., G. Huang, V. Chandrasekar, and E. Gorgucci, 2002: A methodology for estimating the parameters of a gamma raindrop size distribution model from polarimetric radar data: Application to a squall-line event from the TRMM/Brazil campaign. J. Atmos. Oceanic Technol., 19, 633-645, https://doi.org/ 10.1175/1520-0426(2002)019<0633:AMFETP>2.0.CO;2.

_ V. Chandrasekar, J. Hubbert, E. Gorgucci, W. L. Randeu, and M. Schoenhuber, 2003: Raindrop size distribution in different climatic regimes from disdrometer and dual-polarized radar analysis. J. Atmos. Sci., 60, 354-365, https://doi.org/ 10.1175/1520-0469(2003)060<0354:RSDIDC >2.0.CO;2.

Cao, Q. G., and E. Zhang, 2009: Errors in estimating raindrop size distribution parameters employing disdrometer and simulated raindrop spectra. J. Appl. Meteor. Climatol., 48, 406-425, https://doi.org/10.1175/2008JAMC2026.1.

,,-- T. Brandes, T. Schuur, A. Ryzhkov, and K. Ikeda, 2008: Analysis of video disdrometer and polarimetric radar data to characterize rain microphysics in Oklahoma. J. Appl. Meteor. Climatol., 47, 2238-2255, https://doi.org/10.1175/ 2008JAMC1732.1.

Goddard, J. W., J. Tan, and M. Thurai, 1994: Technique for calibration of meteorological radar using differential phase. Electron. Lett., 30, 166-167, https://doi.org/10.1049/el: 19940119.

Gorgucci, E., G. Scarchilli, and V. Chandrasekar, 1999: A procedure to calibrate multiparameter weather radar using properties of the rain medium. IEEE Trans. Geosci. Remote Sens., 37, 269-276, https://doi.org/10.1109/36.739161.

, V. Chandrasekar, V. N. Bringi, and G. Scarchilli, 2002: Estimation of raindrop size distribution parameters from polarimetric radar measurements. J. Atmos. Sci., 59, 2373-2384, https://doi.org/10.1175/1520-0469(2002)059<2373:EORSDP> 2.0.CO;2.

Haddad, Z. S., D. A. Short, S. L. Durden, E. Im, S. H. Hensley, M. B. Grable, and R. A. Black, 1997: A new parameterization of the rain drop size distribution. IEEE Trans. Geosci. Remote Sens., 35, 532-539, https://doi.org/10.1109/36.581961. 
Hagen, M., and S. E. Yuter, 2003: Relations between radar reflectivity, liquid water content, and rainfall rate during the MAPSOP. Quart. J. Roy. Meteor. Soc., 129, 477-493, https:// doi.org/10.1256/qj.02.23.

Huang, H., G. Zhang, and K. Zhao, 2019: Uncertainty in retrieving raindrop size distribution from polarimetric radar measurements. J. Atmos. Oceanic Technol., 36, 585-605, https:// doi.org/10.1175/JTECH-D-18-0107.1.

Kruger, A., and W. F. Krajewski, 2002: Two-dimensional video disdrometer. J. Atmos. Sci., 19, 602-617, https://doi.org/10.1175/ 1520-0426(2002)019<0602:TDVDAD > 2.0.CO;2.

Kumjian, M. R., A. V. Ryzhkov, H. D. Reeves, and T. J. Schuur, 2013: A dual-polarization radar signature of hydrometeor refreezing in winter storms. J. Appl. Meteor. Climatol., 52, 25492566, https://doi.org/10.1175/JAMC-D-12-0311.1.

Lee, G., and I. Zawadzki, 2006: Radar calibration by gage, disdrometer, and polarimetry: Theoretical limit caused by the variability of drop size distribution and application to fast scanning operational radar data. J. Hydrol., 328, 83-97, https:// doi.org/10.1016/j.jhydrol.2005.11.046.

Lohmann, U., F. Luond, and F. Mahrt, 2016: An Introduction to Clouds: From the Microscale to Climate. Cambridge University, Press, 399 pp.

Mcfarquhar, G. M., and R. List, 1993: The effect of curve fits for the disdrometer calibration on raindrop spectra, rainfall rate, and radar reflectivity. J. Appl. Meteor., 32, 774-782, https://doi.org/ 10.1175/1520-0450(1993)032<0774:TEOCFF $>2.0 . C O ; 2$.

Moisseev, D. N., and V. Chandrasekar, 2007: Examination of the $\mu-\Lambda$ relation suggested for drop size distribution parameter. J. Atmos. Oceanic Technol., 24, 847-855, https://doi.org/ 10.1175/JTECH2010.1.

Nešpor, V., W. F. Krajewski, and A. Kruger, 2000: Wind-induced error or rain drop size distribution measurement using a twodimensional video disdrometer. J. Atmos. Oceanic Technol., 17, 1483-1492, https://doi.org/10.1175/1520-0426(2000)017<1483: WIEORS $>2.0 . \mathrm{CO} ; 2$

Park, S. G., and G. W. Lee, 2010: Calibration of radar reflectivity measurements from the KMA operational radar network. Asia-Pac. J. Atmos. Sci., 46, 243-259, https://doi.org/10.1007/ s13143-010-1010-3.

Pruppacher, H. R., and K. V. Beard, 1970: A wind tunnel investigation of the shape of the internal circulation of and shape of water drops falling at terminal velocity in air. Quart. J. Roy. Meteor. Soc., 96, 247-256, https://doi.org/10.1002/qj.49709741117.

Raupach, T. H., and A. Berne, 2015: Correction of raindrop size distributions measured by Parsivel disdrometers, using a twodimensional video disdrometer as a reference. Atmos. Meas. Tech., 8, 343-365, https://doi.org/10.5194/amt-8-343-2015.

Ryzhkov, A. V., and D. S. Zrnić, 1998: Discrimination between rain and snow with a polarimetric radar. J. Appl. Meteor., 37,
1228-1240, https://doi.org/10.1175/1520-0450(1998)037<1228: DBRASW $>2.0 . \mathrm{CO} ; 2$.

Sheppard, B. E., and P. I. Joe, 1994: Comparison of raindrop size distribution measurements by a Joss-Waldvogel disdrometer, a PMS2DG spectrometer, and a POSS Doppler radar. J. Atmos. Oceanic Technol., 11, 874-887, https://doi.org/10.1175/15200426(1994)011<0874:CORSDM>2.0.CO;2.

Steiner, M., J. A. Smith, and R. Uiilenhoest, 2004: A microphysical interpretation of radar reflectivity-rain rate relationships. J. Atmos. Sci., 61, 1114-1131, https://doi.org/10.1175/15200469(2004)061<1114:AMIORR > 2.0.CO;2.

Tokay, A., A. Kruger, and W. F. Krajewski, 2001: Comparison of drop size distribution measurements by impact and optical disdrometers. J. Appl. Meteor., 40, 2083-2097, https://doi.org/ 10.1175/1520-0450(2001)040<2083:CODSDM >2.0.CO;2.

- D. B. Wolff, K. R. Wolff, and P. Bashor, 2003: Rain gauge and disdrometer measurements during the Keys Area Microphysics Project (KAMP). J. Atmos. Oceanic Technol., 20, 1460-1477, https://doi.org/10.1175/1520-0426(2003)020<1460:RGADMD > 2.0.CO;2.

Ulbrich, C. W., 1983: Natural variations in the analytical form of the raindrop size distribution. J. Climate Appl. Meteor., 22, 1764-1775, https://doi.org/10.1175/1520-0450(1983)022<1764: NVITAF $>2.0 . \mathrm{CO} ; 2$.

— , and D. Atlas, 1998: Rainfall microphysics and radar properties: Analysis methods for drop size spectra. J. Appl. Meteor., 37, 912-923, https://doi.org/10.1175/1520-0450(1998) 037<0912:RMARPA $>2.0 . C O ; 2$.

Vivekanandan, J., G. Zhang, and E. Brandes, 2004: Polarimetric radar estimators based on a constrained gamma drop size distribution model. J. Appl. Meteor., 43, 217-230, https://doi.org/ 10.1175/1520-0450(2004)043<0217:PREBOA > 2.0.CO;2.

Williams, C. R., and Coauthors, 2014: Describing the shape of raindrop size distributions using uncorrelated raindrop mass spectrum parameters. J. Appl. Meteor. Climatol., 53, 12821296, https://doi.org/10.1175/JAMC-D-13-076.1.

Zhang, G., 2016: Weather Radar Polarimetry. 1st ed. CRC Press, $322 \mathrm{pp}$.

_ J. Jivekanandan, and E. Brandes, 2001: A method for estimating rain rate and drop size distribution from polarimetric radar measurements. IEEE Trans. Geosci. Remote Sens., 39, 830-841, https://doi.org/10.1109/36.917906.

$\ldots,-,-$, R. Meneghini, and T. Kozu, 2003: The shapeslope relation in gamma raindrop size distribution: Statistical error or useful information? J. Atmos. Oceanic Technol., 20 , 1106-1119, https://doi.org/10.1175/1520-0426(2003)020<1106: TSRIOG $>2.0 . \mathrm{CO} ; 2$.

_ rain microphysics with disdrometer and radar observations. J. Atmos. Sci., 63, 1273-1290, https://doi.org/10.1175/JAS3680.1. 